Portland State University

PDXScholar

Fall 12-4-2018

\title{
Characterizing Temperature Variability States Across Southern South America and Associated Synoptic- Scale Meteorological Patterns
}

Judah Adam Detzer

Portland State University

Follow this and additional works at: https://pdxscholar.library.pdx.edu/open_access_etds

Part of the Meteorology Commons, and the Physical and Environmental Geography Commons Let us know how access to this document benefits you.

Recommended Citation

Detzer, Judah Adam, "Characterizing Temperature Variability States Across Southern South America and Associated Synoptic-Scale Meteorological Patterns" (2018). Dissertations and Theses. Paper 4679. https://doi.org/10.15760/etd.6563

This Thesis is brought to you for free and open access. It has been accepted for inclusion in Dissertations and Theses by an authorized administrator of PDXScholar. Please contact us if we can make this document more accessible: pdxscholar@pdx.edu. 
Characterizing Temperature Variability States Across Southern South America and Associated Synoptic-Scale Meteorological Patterns

by

Judah Adam Detzer

A thesis submitted in partial fulfillment of the requirements for the degree of

\author{
Master of Science \\ in \\ Geography
}

Thesis Committee:

Paul Loikith, Chair

Andrés Holz

Geoffrey Duh

Portland State University

2018 


\begin{abstract}
The aim of this thesis is to understand spatiotemporal temperature variability in southern South America by identifying overarching temperature variability states and their associated synoptic-scale meteorological patterns. Further, the temporal frequency of occurrence of those temperature variability states is investigated as is the role of recurrent low-frequency modes of climate variability (El Niño Southern Oscillation and the Southern Annular Mode) on temperature variability. K-means cluster analysis is used to group all months during the period 1980-2015 into four primary categories for summer and winter separately. Monthly maps of temperature anomalies are provided as input to the k-means algorithm and the resulting temperature variability states are the composites of temperature anomaly maps for months assigned to each cluster, illustrating the primary spatial patterns of temperature variability over Southern South America. Composites of synoptic-scale meteorological patterns (wind, geopotential height, and moisture fields) are calculated for months assigned to each cluster to better diagnose the driving meteorology associated with these patterns of temperature variability. Results show that in summer surface wind direction and geopotential height are robust indicators of temperature variability patterns, while in winter jet stream winds are important for diagnosing equatorward excursions of cold air and poleward excursions of warm air. According to the results the El Niño Southern Oscillation and the Southern Annular Mode exhibit some relationship with temperature variability state frequency, with some states more associated with these two modes than others, however they do not appear to be primary drivers of any of the temperature variability states.
\end{abstract}




\section{Acknowledgements}

I would like to acknowledge the support and encouragement of my graduate advisor, Dr. Paul Loikith. His commitment to research, teaching, and inclusivity makes working in his lab an honor and a privilege.

I would like to thank the members of the Climate Science Lab for their generous support and enthusiastic feedback throughout the development of my research. My work has benefited greatly from their insight. Specifically I would like to acknowledge Emily Slinskey and Christina Aragon, both of whom have a tireless work ethic and unbounded scientific curiosity that continues to inspire me.

Thank you also to my committee members, Dr. Andrés Holz and Dr. Geoffrey Duh, for your thoughtful insights on this work.

Finally, I want to thank my wife Harmony for her loving support. Thank you for helping me see what I was capable of, even when I could not.

This paper is dedicated to my parents, Patty and Eric.

Support was provided by the US National Science Foundation (NSF)

AGS-1547899. 


\section{Table of Contents}

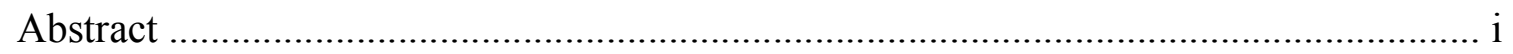

Acknowledgements ................................................................................................ ii

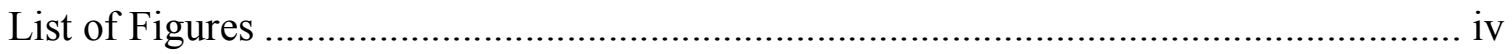

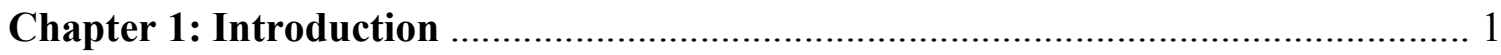

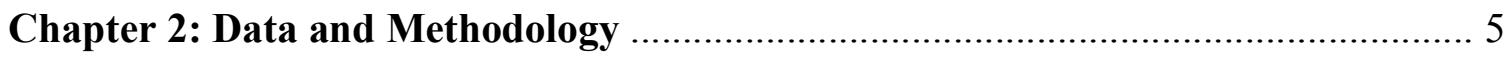

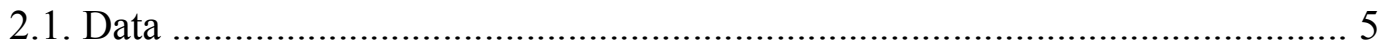

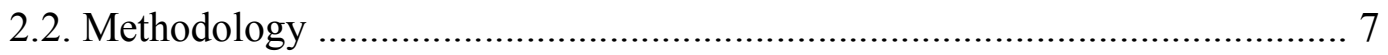

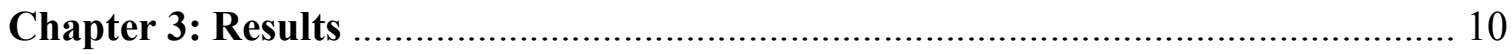

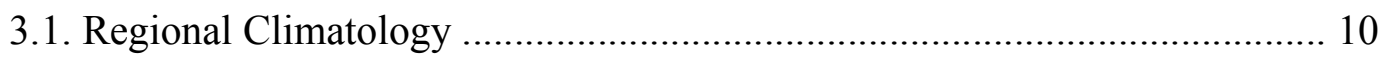

3.2. Temperature variability states and associated drivers ............................ 11

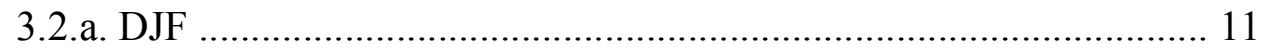

3.2.b. JJA ….......................................................................... 17

3.3. Frequency of occurrence of TVS per season JJA .................................. 21

3.4. Influence of recurrent modes of climate variability on TVSs .................... 22

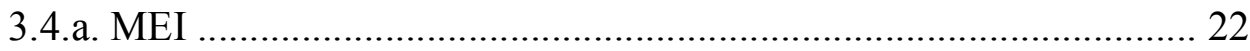

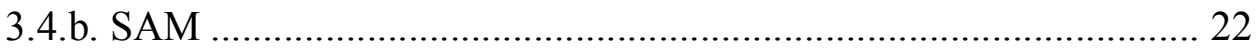

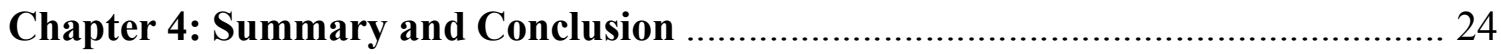

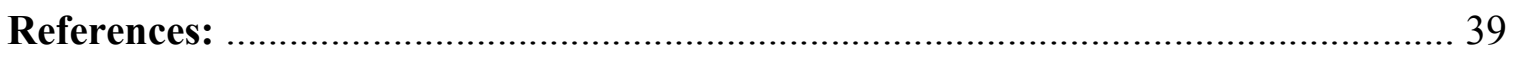

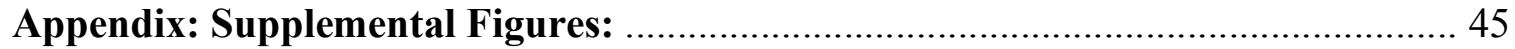




\section{List of Figures}

Figure 1. Total field composites for temperature, integrated water vapor, and precipitation for DJF and JJA

Figure 2. Total field geopotential height composites at $850 \mathrm{hPa}$ with wind at $850 \mathrm{hPa}$ layered over top. Fields are separated into DJF (a) and JJA (b) ..................... 28

Figure 3. Total field wind composites at $250 \mathrm{hPa}$ for JJA only 28

Figure 4. TVSs for DJF

Figure 5. Composites of geopotential height anomalies and wind anomalies at $850 \mathrm{hPa}$

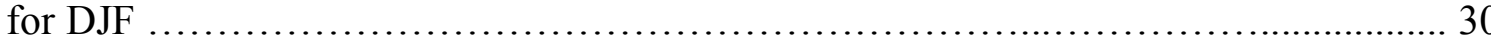

Figure 6. Composite of integrated water vapor anomalies for DJF 31

Figure 7. Composite of precipitation fraction for DJF 32

Figure 8. Same as Figure 4 except for JJA 33

Figure 9. Same as Figure 5 except for JJA 34 
Figure 10. Wind at $250 \mathrm{hPa}$ for JJA

Figure 11. Same as Figure 6 except for JJA 35

Figure 12. Same as Figure 7 except for JJA 36

Figure 13. Occurrence and frequency of TVS for DJF and JJA …....................... 37

Figure 14. ENSO and SAM index values associated with months assigned to each TVS

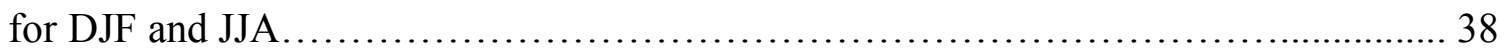




\section{Chapter 1: Introduction}

Southern South America (SSA), defined here as all landmass south of the Tropic of Capricorn, is a region with a dynamic climate owing to its lengthy meridional extension and pronounced orographic features. The geography of SSA encompasses a diverse range of climate regions that includes a large region of steppe, the driest desert in the world, and a massive river basin. Extending along the western edge of the continent is the Andes Mountain range, an important feature which has a strong impact on wind and precipitation patterns across the region (Garreaud, 2009). While the northernmost part of SSA borders the tropics, the southern tip of Patagonia extends far into the mid-latitudes. Further, the Pacific and Atlantic Oceans frame the continent and have a strong impact on coastal temperatures and atmospheric circulation patterns. The climate of SSA is heavily impacted by the circumpolar storm track across Patagonia while the northernmost region of SSA is heavily influenced by the continental low-level jet.

It is well documented in the literature that temperatures have been increasing across parts of South America in recent decades (e.g. Barkhordarian et al., 2017de Barros et al., 2017; IPCC, 2014). And while there have been many studies that have focused on precipitation variability and change (e.g. Grimm and Tedeschi, 2009; Kayano et al., 2011; Torralba et al., 2015), there are far fewer concerning temperature and temperature variability. Temperature trends across the continent of South America are heterogenous (Rusticucci, 2012) and therefore, this thesis paper focuses on SSA, not only because the climate of SSA is substantially different from that of tropical South America but also because of its strong seasonality. 
Like most parts of the world, human activity over SSA is greatly affected by the climate, and specifically temperature variability patterns. Temperature variability is a critical component for both the health of the inhabitants and the economy of SSA (Sura, 2011). Agricultural regions and the crops grown there are determined by the climate of SSA and can be adversely affected by shifts in surface temperature distribution patterns. For instance, Masiokas et al. (2014) found that in northwestern Patagonia widespread glacier recession is correlated with increasing temperatures and reduced precipitation during the 1912-2002 study period, which could lead to negative impacts on crop yield. The Pampas is a large fertile region of Argentina where the economy is based on agriculture and livestock. This region experiences intermittent periods of drought and floods that may be seriously impacted by shifts in temperature variability patterns (Aliaga, 2017). In particular, temperature variability patterns can have a profound effect on water resources, including the loss of snowpack and the timing of glacier melt while also impacting precipitation (Bradley et al., 2009; Buytaert and Breuer, 2013). Depleted water resources are a key factor in the region as this would increase irrigation costs, thus raising the cost of food and may reduce water quality, according to the Economical Council for Latin America (Marengo et al., 2014).

One way to diagnose the key drivers that lead to preferred states of spatiotemporal temperature variability is to analyze the associated synoptic-scale meteorological patterns. Temperature variability has many drivers in this part of the world, here synoptic-scale meteorological patterns (SSMPs) are investigated in order to understand the dynamic and thermodynamic drivers associated with temperature variability. SSMPs (sometimes referred to as large-scale meteorological patterns) are tropospheric-deep 
weather features with a temporal duration of days to weeks and are of a horizontal spatial scale on the order of thousands of kilometers, such as mid-latitude and extratropical cyclones (Garreaud, 2009). The application of SSMPs is a well-established method for understanding weather and climate variability, especially for elucidating warm and cold air advection via surface winds. Multiple studies have applied SSMPs to diagnose the drivers of extreme temperature events in a diverse range of regions (e.g. Loikith and Broccoli, 2012; Pezza et al., 2012; Cassano et al., 2016). Pampuch et al. (2014) investigated the importance of circulation patterns and moisture transport in southern Brazil. Their results indicate that these patterns are a key indicator for understanding extreme drying events in the region. Solman and Menéndez (2002) investigated the role of recurrent atmospheric circulation patterns and identified a significant influence of persistent circulation patterns on the local climate over Patagonia and northern Argentina. Berman et al. (2012) specifically looked at seasonal temperature variability in eastern Patagonia. Their study found strong connections between temperature patterns in eastern Patagonia with both circulation anomalies and the outbreak of cold air from the Antarctic onto the continent. While each of these papers addresses the effects of circulation patterns on the climate of specific regions of SSA, there is still a need to characterize more fully the meteorological variables associated with dominant temperature variability states across the wider domain.

In addition to synoptic-scale drivers, teleconnections from atmosphere and oceanatmosphere drivers have also been shown to be influential in this region (Grimm et al., 2000; Garreaud et al., 2009). Other studies have looked at modes of climate variability such as the El Niño Southern Oscillation (ENSO) (Kayano et al., 2017) and the Southern 
Annular Mode (SAM) and their impact on temperature variability patterns (Gillett et al., 2006; Silvestri and Vera, 2009) and monthly temperature extremes (Loikith et al., 2017). The impacts of ENSO are most often associated with climate impacts in the tropical region of South America as Kayano et al. (2017) argue, while Thompson and Wallace (2000) found that the positive and negative phases of the SAM are correlated with warm and cold temperature anomalies across SSA, respectively.

By characterizing TVSs and their associated SSMPs a basis for understanding temperature variability patterns during the 36 year period, $1980-2015$ is provided. The goals of this thesis are to (i) identify temperature variability states across SSA, (ii) characterize the synoptic-scale meteorological patterns that are associated with each temperature variability state, (iii) understand the temporal frequency of occurrence of the temperature variability states, and (iv) investigate the association between the identified TVSs with ENSO and the SAM.

This thesis is organized as follows. The data and methodology used in this study are described in Chapter 2 . Chapter 3 describes the results of the study and the main conclusions are summarized in Chapter 4. 


\section{Chapter 2: Data and Methodology}

\subsection{Data}

The Climate Research Unit Time-series data Version 4.01 (CRUv4; Harris et al., 2014) is used as the primary data set for surface temperature. CRUv4 is the most recent version of the data set covering the period $1901-2016$ and is provided on a $0.5^{\circ} \mathrm{x}$ $0.5^{\circ}$ latitude/longitude grid. For this analysis the mean surface temperature product is used, which is based on station data where available. Between 1 and 8 stations contribute to a grid cell at any time step, and observations take precedence over synthetic data when both are present (see Figure S1). This version has improved upon subsequent versions by the use of angular-distance weighting for gridding the monthly anomalies. A more complete description of the ADW method is described in New et al. (2000). CRUv4 data are based on monthly observational data calculated from daily or sub-daily data.

The CRUv4 data set is employed due to the lack of spatially consistent, highquality, station data across southern South America. Observational stations in this region are sparse and spatially heterogeneous, which makes the gridded CRUv4 an attractive alternative. However, because CRUv4 is based on station data, observational uncertainty is of concern. In order to assess observational uncertainty, CRUv4 is compared to three additional gridded surface temperature data sets (Figures S2-S7). Two are reanalysis products: The Modern-Era Retrospective analysis for Research and Applications, Version 2, MERRA2 (Gelaro et al., 2017) and The European Centre for Medium-Range Weather Forecasting's ERA-Interim product (Dee et al., 2011). The University of Delaware gridded station (UDel) data set is also applied. All other meteorological fields 
(geopotential height and wind at $850 \mathrm{hPa}$, wind at $250 \mathrm{hPa}$, integrated water vapor, and precipitation) are from MERRA-2.

Climate indices for the El Niño Southern Oscillation (ENSO) and the Southern Annular Mode (SAM) are obtained from the U.S. National Oceanic and Atmospheric Administration's Earth System Research Laboratory. For ENSO the Multivariate Niño Index (MEI) is used and for the SAM the Antarctic Oscillation (AAO) index is employed. Both indices are freely available via the web (http://www.esrl.noaa.gov/psd/data/climateindices/list/). The MEI is based on tropical Pacific Comprehensive Ocean-Atmosphere Data Set records and is a multivariate measure of the ENSO signal as expressed in the first principal component of six observed variables over the tropical Pacific (Wolter \& Timlin, 1998). The MEI is a bi-monthly index and as such the June value, for example, is constructed using data from May and June. For this analysis the second of the two months in the analysis is referred to, therefore in the analysis when the austral winter season of June-July-August (JJA) is discussed, the values for May and June, June and July, and July and August are being used. The SAM index, also called the AAO, is based on the zonal atmospheric pressure difference over the southern hemisphere mid and high latitudes and is defined by the leading empirical orthogonal function of the sea level pressure (SLP) field or zonally symmetric geopotential height or zonal wind fields south of $20^{\circ} \mathrm{S}$ latitude (Thompson \& Wallace, 2000). 


\subsection{Methodology}

SSA is here defined as land area south of $23.5^{\circ} \mathrm{S}$ and all analysis is performed over the years 1980-2015. All anomalies are computed by removing the monthly 36-year seasonal cycle from each grid point. All analyses are stratified by meteorological season and are defined as December, January, February (DJF); March, April, May (MAM); June, July, August (JJA); September, October, November (SON). Further, the student ttest is applied to the meteorological variables in order to identify regions that do not meet the $5 \%$ confidence threshold for being statistically significantly different from zero.

Temperature variability states are identified by applying the k-means clustering algorithm to each season of the temperature anomaly data set. The clustering algorithm assigns months whose temperature anomaly patterns across SSA are most similar to one another to the same cluster. This partitioning of the seasonal temperature data into clusters minimizes and maximizes the difference within and between each cluster respectively (MacQueen, 1967). Next, composites of the temperature anomalies are calculated for all months assigned to a cluster and herein these patterns are referred to as temperature variability states (TVSs). The goal in identifying TVSs is to find a small number of representative states that capture a large fraction of temperature variability within spatial patterns that describe the observed data.

A number of analysis approaches could be used to elucidate spatio-temporal temperature variability patterns. Clustering is chosen over Empirical Orthogonal Functions (EOF) analysis to arrive at individual states with each month in the time period assigned to a TVS. This is a different goal than would be accomplished using EOF analysis, which would highlight the primary patterns of temperature covariability (Lau 
and Nath 2012). One of the key tasks in using this non-hierarchical k-means clustering method is determining the number of clusters to use in the analysis. Here a hybrid approach is applied to determine the choice of four clusters. First, Silhouette Value Analysis (SVA) is applied to each season of temperature anomaly data in order to determine the appropriate number of clusters to use. The SVA is run for two to twelve clusters in order to capture a wide range of possible optimal solutions. SVA measures how well the number of clusters fits the data set being applied. In this case the higher the local maxima of the silhouette value the better the match between the data and the number of clusters chosen. Conversely, a low or negative number indicates a poor fit of the data to the number of clusters. According SVA either three or four clusters would be appropriate for either season. Three or fewer clusters do not sufficiently capture the amount of variability in the data when visually inspected. However, when applying five or more clusters, repeating patterns emerge. Through this hybrid process a balance is found between a large enough number of clusters such that distinct temperature variability states are captured while not having so large a k-value that patterns begins to repeat.

Before performing k-means on the temperature anomaly data it is normalized by dividing the anomalies by the temporal standard deviation of the anomalies at each grid cell. This is done in order to account for the impact that grid cells at higher latitudes will have, owing to their greater temperature variability when compared to those grid cells closer to the equator, which have less temperature variability. In order to compensate for the meridian convergence toward higher latitudes an area-weighted mean is performed by calculating the fraction of change that occurs at each grid cell, where those grid cells 
closest to the equator change the least and the grid cells closest to the pole change the most. This is done by calculating the product of the anomalies and the square root of the cosine of the latitude at each grid cell. 


\section{Chapter 3: Results}

\subsection{Regional climatology}

To understand what the variability described by the TVSs and associated meteorological fields is in reference to, Figures 1-3 show climatological averages of key quantities for each season. Figure 1a,b shows the climatological average seasonal temperature pattern for DJF and JJA. The warmest average temperatures are found toward the north-central interior portion of SSA while the coldest temperatures are at the highest altitudes along the Andes Mountains and along the southernmost portions of the region. Figure 1c,d shows the climatological average seasonal integrated water vapor (IWV) pattern for DJF and JJA. In both seasons the largest amount of IWV is found in the northern region of the domain, east of the Andes Mountains, with higher amounts in DJF compared with JJA, thermodynamically consistent with a warmer atmosphere holding greater amounts of water vapor. Figure 1e,f shows the climatological average seasonal precipitation pattern for DJF and JJA. During DJF the largest amount of precipitation occurs in the northeastern region of the domain and then gradually declines towards Patagonia. Most of Patagonia receives small amounts precipitation while relatively high amounts fall along the far southwest coast of Chile. JJA is considerably drier than DJF throughout much of the domain, except along the west coast of Patagonia. Dynamic fields, geopotential height $(\mathrm{Z})$ and wind at $850 \mathrm{hPa}$ are shown in Figure 2. During DJF (Figure 2a) there are two regions of maximum Z850. One is in the tropical Pacific Ocean and the other in the tropical Atlantic Ocean, coinciding with the climatological location of the subtropical high-pressure centers. In JJA (Figure 2b), the region of highest Z850 over the Pacific is slightly weaker than in DJF while the 
maximum centered over the Atlantic stretches farther westward. Both high Z850 regions are shifted northward in JJA compared with DJF, expanding the region within the center of the mid-latitude westerlies. Figure 3 shows climatological average wind speed at 250 $\mathrm{hPa}$ for JJA to highlight the seasonal placement of the jet stream in order to appreciate how the equatorward migration of maximum baroclinicity during the cool season in the mid-latitudes affects temperature variability. Note that only JJA is shown for $250 \mathrm{hPa}$ winds because, for reasons explained below, this variable is only analyzed in relation to temperature variability during JJA.

\subsection{Temperature variability states and associated drivers}

\section{2.a. DJF}

Figure 4 shows the results of the k-means cluster analysis, with each panel representing a TVS, referred to herein by the numbered labels at the bottom right of each panel. Two distinct modes of temperature variability are present across the four TVSs, each represented by two TVSs that resemble each other but with anomalies of opposite sign: TVS1 and TVS4; TVS2 and TVS3. TVS1 and TVS4 are mostly spatially homogenous in their temperature anomaly pattern, while the magnitude of TVS1's anomalies are more strongly positive than TVS4's are negative, indicating that the two patterns are not completely symmetrical. TVS2 and TVS3 have similar spatial northsouth dipole patterns, only opposite in sign from one another. Positive and negative anomalies are divided at approximately $40^{\circ} \mathrm{S}$ latitude in both TVS2 and TVS3.

Figure 5 shows composites of Z850 anomalies and $850 \mathrm{hPa}$ wind anomalies for months assigned to each of the four clusters in Figure 4. In other words, panel (a) in 
Figure 5 is a composite of $\mathrm{Z} 850$ and $850 \mathrm{hPa}$ wind anomalies computed over all months comprising TVS1 (Figure 4). The composite in Figure 5a is characterized by negative Z850 anomalies to the west of SSA and positive Z850 anomalies over most of Chile and extending east across Argentina into the Atlantic. A weak negative Z850 anomaly is also centered over eastern Brazil. These anomalies in the Z850 field promote anomalous winds which can readily be connected with the temperature anomaly pattern in TVS1. For example, the warmest anomalies in TVS1 coincide with anomalous northerly winds and positive geopotential height anomalies. The small area of weak temperature anomalies in the northeastern part of the domain is associated with easterly wind anomalies resulting from the positive Z850 anomaly center to the south and negative Z850 anomaly to the north. This brings influence from cooler Atlantic air as opposed to warmer air from the interior.

Figure $5 b$, the composite patterns associated with TVS2, is characterized by negative Z850 anomalies nearly centered on the southern tip of Patagonia with positive Z850 anomalies in southeastern Brazil. Z850 field anomalies are associated with anomalous westerly winds across Patagonia and anomalous northerly winds from the tropics. These anomalous wind patterns correspond to TVS2, where anomalously strong westerly wind is coincident with relatively modest negative temperature anomalies in Patagonia and anomalous northerly wind is coincident with positive temperature anomalies in the northern half of the domain.

Figure 5c, associated with TVS3, is characterized by positive Z850 anomalies across southern Patagonia with negative Z850 anomalies in southeastern Brazil. Note that this pattern is similar to the pattern in Figure 5b, but opposite in sign. This corresponds to 
TVS2 being similar to TVS3, but also opposite in sign, suggestive of this apparent "mode" of temperature variability having close connection to a "mode" of low level circulation. Most of the SSA domain is associated with positive Z850 anomalies, while TVS3 is characterized by a north-south pattern with negative temperature anomalies in the north and positive temperature in the south. Positive temperature anomalies of TVS3 are associated with anomalous easterly wind and positive Z850 anomalies whereas negative temperature anomalies are associated with anomalous southerly wind from the Atlantic into La Plata Basin. This explains the dynamics contributing to the north-south dipole temperature anomaly pattern in TVS3, where negative anomalies are associated with advection of cool Atlantic Ocean air into a climatologically warm region while positive anomalies are associated with a weakening or reversal of the westerlies and some influence in the low level flow from warmer lower latitudes into a climatologically cooler region.

Figure $5 \mathrm{~d}$ is characterized by a negative Z850 anomaly pattern over SSA and a large region of positive Z850 anomalies centered over the Pacific Ocean and stretching into the Atlantic. This Z850 anomaly pattern promotes wind with a southerly component across the southern tip of Patagonia. The negative temperature anomalies that dominate TVS4 are largely collocated with the weak negative Z850 values in Figure 5d. Additionally, some influence of high latitude air is likely influential in the negative temperature anomalies, although $850 \mathrm{hPa}$ wind anomalies are generally weak across the region of most negative temperature anomalies in TVS4. While not perfectly symmetrical, the pattern in Figures 5a and 5d are largely similar but opposite in sign, consistent with TVS1 versus TVS4. This indicates that DJF months preferentially fit 
within two phases of two different regimes in surface temperature (i.e. TVS) and low level circulation, with low level circulation dynamically linked with the TVS.

Figure 6 shows composites for anomalies in integrated water vapor (IWV) for months assigned to each cluster. In Figure $6 a, d$, positive and negative water vapor anomaly patterns correspond with positive and negative temperature anomaly patterns, respectively, except in the northeastern region of SSA. Anomalies in wind and Z at 850 $\mathrm{hPa}$ help diagnose the conditions associated with the anomalous IWV since most atmospheric water vapor is concentrated in the lower levels of the atmosphere. Here, the anomalous Z850 low helps explain the negative IWV values in Figure 6a. The Z850 low promotes onshore winds from the Atlantic Ocean, which relative to the very warm and humid interior to the north, have low values of IWV. This isn't, however, associated with cool temperature anomalies in TVS1, indicating that the northeastern part of the domain is dominated by warm and dry conditions while the atmospheric column is anomalously moist and warm across the rest of the domain for months assigned to cluster 1.

Conversely, the opposite pattern found in Figure $6 \mathrm{~d}$ is not associated with a notable Z850 high in the northeast, but rather positive IWV anomalies appear to be driven by northerly wind anomalies in the lower levels, advecting moist air from the tropics. The weak negative temperature anomalies coincident with this feature in TVS4 suggest the northerly wind anomalies, while coming from a warm and moist region, also bring cloud cover, keeping temperatures below average. Across the rest of the domain, TVS4 is associated with anomalously cool and dry conditions.

Figure $6 \mathrm{~b}, 6 \mathrm{c}$ display a similar pattern to one another, only with regions of positive and negative IWV anomalies geographically reversed. This is mostly due to the direction 
of anomalous $850 \mathrm{hPa}$ winds across both Patagonia and the northeastern region of the domain. Figure $6 \mathrm{~b}$ is associated with TVS2, which is characterized by positive temperature anomalies in the north and negative anomalies in the south. The anomalous winds across Patagonia are enhanced westerlies which advect cool dry air from the Pacific Ocean across the region leading to cooler than average surface temperatures while warm, moisture laden air from the tropical interior leaves the northeastern region with positive IWV anomalies. This pattern is reversed in Figure $6 \mathrm{c}$ so that northeastern SSA has anomalously low IWV values whereas Patagonia contains anomalously high IWV values. Across Patagonia, in Figure 6c, are anomalous easterly winds that oppose the climatological westerly winds while southerly winds in northeastern SSA also oppose the climatological northerly winds and result in relatively cool Atlantic Ocean air, with relatively low IWV advecting inland. In both Figure $6 \mathrm{~b}$ and Figure $6 \mathrm{c}$ anomalous positive and negative surface temperatures are directly associated with positive and negative IWV anomalies, thermodynamically consistent with warmer air having a higher water vapor holding capacity and dynamically consistent with lower atmospheric advective processes indicated in Figure 5.

To further link circulation and atmospheric moisture with each TVS, Figure 7 shows composites of precipitation anomalies, computed as fractions of mean precipitation (a value of one indicates no anomaly). In general, precipitation does not appear to be closely linked with temperature variability over SSA during DJF, although some connections can be made. Figure $8 \mathrm{a}$, associated with the nearly uniformly warm TVS1, is also nearly uniformly drier than average. With the exception of some small regions of positive precipitation anomalies, this further indicates that months assigned to 
cluster 1 tend to be associated with both warm and dry conditions. Figure $7 \mathrm{~d}$ shows a similar but opposite pattern of precipitation anomalies that in conjunction with the widespread negative temperature anomalies characterizing TVS4 indicates cooler and wetter than average conditions for these months. The cool anomalies in TVS4 are therefore linked to low level cool air advection (Figure 5d) and more precipitation than average. The negative IWV anomalies for months assigned to cluster 4 are likely due to the thermodynamic property of cooler air holding less water vapor, which may partially explain why there are positive precipitation anomalies coincident with lower than average IWV.

Precipitation anomalies in $7 \mathrm{~b}$ show greater than average precipitation in the northeastern region and western Patagonia while there is less than average precipitation in the central interior with a nearly opposite pattern in Figure 8c. The position of the anomalous Z850 system over Patagonia influences surface wind anomalies throughout the region. For example, in Figure $7 \mathrm{~b}$ where negative Z850 anomalies are associated with enhanced westerly winds from the Pacific, these winds and associated low level moisture are lifted by the western slope of the Andes thus producing precipitation. Northerly winds in the northeastern region are promoted via the positive Z850 anomaly system; these winds bring not only warm moist air from the tropics but are associated with greater than average precipitation and positive temperature anomalies in the region. Conversely, Figure 7c is associated a positive Z850 anomaly over Patagonia which promotes easterly wind anomalies across Patagonia and southerly winds over the northeastern region of the domain. These southerly winds originate from the Atlantic Ocean and are therefore cooler and drier than when the wind is directed out of the inland north. 


\section{2.b. JJA}

Figure 8 shows the TVSs for JJA, in the same format as for DJF in Figure 4. In JJA, TVS1 and TVS4 are both nearly homogenous in their temperature anomaly patterns, only opposite in sign, with the exception of the most southern reaches of the domain. TVS2 and TVS3 are divided into a north-south dipole pattern which splits the northeastern region from the rest of the domain. In TVS2, the northeast exhibits modest negative temperature anomalies while the rest of the domain shows positive anomalies which get larger towards the south. In TVS3, the negative temperature anomalies in the southern two-thirds of the domain become relatively strong towards the south, while the northern quarter of SSA shows positive anomalies of generally moderate magnitude.

Figure 9 shows the $\mathrm{Z} 850$ anomalies and $850 \mathrm{hPa}$ wind anomalies concurrent with the months assigned to each cluster for JJA, as in Figure 5 for DJF. The highest magnitude of temperature anomalies (positive or negative) most frequently occur on the dividing line between positive and negative Z850 anomaly systems, where anomalous warm or cold air advection is strongest. While this placement is slightly different than DJF, anomalous wind direction is still the strongest indicator of anomalous temperature. Positive and negative temperature anomalies are associated with anomalous northerly and southerly winds, respectively. This is evident in Figure 9a where strong positive and negative Z850 anomaly patterns meet over northern SSA. The positive Z850 pattern promotes warm air advection out of the interior of the continent while the negative Z850 pattern brings cold air from the mid-latitude eastern Pacific Ocean which is likely warmed adiabatically as it sinks over the eastern slope of the Andes Mountains. These 
Z850 patterns are coincident with homogenously positive temperature anomalies in TVS1. A similar pattern, only opposite in sign, occurs in Figure 9d, where the positive Z850 anomaly pattern now promotes cold air advection from the high-latitude Atlantic Ocean while southerly wind across the northeastern region of the domain is associated with the negative Z850 anomaly offshore from southern Brazil. Both are coincident with negative temperature anomalies.

Figure $9 \mathrm{~b}$ shows a strongly negative Z850 anomaly pattern in the southeastern Pacific Ocean and a positive Z850 anomaly pattern over the rest of the domain. Associated with this pattern is TVS2 which shows positive temperature anomalies across much of the domain, with negative anomalies in the northeastern corner. The zonal placement of the Z850 anomaly fosters enhanced northwesterly winds along the western coast of Patagonia which may be advecting some anomalously warm air from the north contributing to the positive temperature anomalies in TVS2. In the northeastern region of the domain anomalous winds from the south advect relatively cool Atlantic Ocean air into a region that is climatologically warm, thus leaving this region anomalously cool. In Figure 9c the positive Z850 anomaly pattern promotes anomalous winds from the south which advects cool air towards the continent resulting in Patagonia being anomalously cold in TVS3. Meanwhile there are relatively weak anomalous winds out of the north in the northeastern region which are associated with positive temperature anomalies.

Figure 10 shows composites of $250 \mathrm{hPa}$ wind speed for months assigned to each cluster, to assess the influence of the jet stream on each TVS. An analogous analysis is not shown for DJF as jet dynamics were found to be less directly influential on TVSs in summer. While cluster to cluster differences in $250 \mathrm{hPa}$ wind speed and jet stream 
location are subtle, the differences do aid in diagnosing the dynamics associated with each TVS. Figure 10a shows a well-defined jet stream that is shifted south of its climatological average location (see Figure 2). This southward excursion of the jet is coincident with warmer than average temperatures across much of the domain in TVS1, with the southernmost part of SSA located poleward of the jet axis and consequently does not exhibit warm temperature anomalies. The pattern in Figure 10d, which corresponds to the negative temperature anomaly dominated TVS4, shows a distinct northward displacement of the $250 \mathrm{hPa}$ jet axis, consistent with a northward excursion of cold high latitude air. Figure 10b is characterized by a relatively weak, less zonally in-tact $250 \mathrm{hPa}$ jet, with the main jet axis well to the north of the climatological mean. This is consistent with the positive temperature anomalies over most of the domain as the $250 \mathrm{hPa}$ wind pattern is suggestive of upper-level ridging. The jet stream in Figure 10c, on the other hand, is especially strong and centered farther south than in Figure 10b. Corresponding to TVS3, the jet clearly aligns with the baroclinic transition, evident at the surface, from the strong negative temperature anomalies in the south to the weaker warm anomalies in the north.

In Figure 11 the thermodynamic connection between IWV anomalies and surface temperature anomalies for JJA is shown. Unlike in DJF, temperature anomalies in each TVS generally correlate with IWV anomaly so that positive and negative IWV anomalies occur where there are positive and negative temperature anomalies, respectively. In Figure 11a,d there are nearly identical IWV anomaly patterns that are opposite in sign, just as there are for temperature anomalies in TVS1 and TVS4. These patterns contain mostly homogenous anomalies throughout the domain for both IWV and temperature. In 
Figure $11 \mathrm{~b}, \mathrm{c}$ the patterns are again nearly identical but opposite in sign, but are now divided into three distinct regions. The northeastern region and the region of southern Chile which have the same sign, and the rest of domain which is opposite in sign from the other two. For the region of southern Chile, positive and negative IWV anomalies are associated with onshore and offshore wind anomalies, respectively. In the other two regions (which are opposite in sign), anomalous wind direction is directly tied to IWV anomaly patterns. Onshore winds from the Atlantic Ocean bring cool air that is associated with negative temperature and IWV anomalies, while winds from the north bring warm moist air from the tropics that are associated with positive temperature and IWV anomalies.

In Figure 12, precipitation fraction composites are characterized for JJA. In Figure 12a and Figure 12d, greater than and less than average precipitation is coincident with positive and negative temperature anomalies, respectively. In Figure 12a moisture laden northerly wind brings water vapor from the tropics and promotes greater than average precipitation throughout much SSA while in $12 \mathrm{~d}$ cold dry air from the southwestern Atlantic is associated with less than average precipitation. Of note for JJA, warmer temperatures are associated with greater than average precipitation in $12 \mathrm{a}$ and $12 \mathrm{~d}$ indicating that temperature anomalies are not directly linked to radiative warming at the surface. However, in Figure 12b,c greater than average precipitation occurs near the dividing line between the positive and negative temperature anomalies of TVS2 and TVS3, as well as the dividing line between positive and negative IWV anomalies, suggesting synoptic scale frontal systems are associated with precipitation here. In both Figure $12 \mathrm{~b}$ and Figure 12c, positive precipitation anomalies generally line up along 
gradients in temperature, also indicative of synoptic-scale forcing from fronts and midlatitude cyclones along a baroclinic zone.

\subsection{Frequency of occurrence of TVSs per season}

To investigate the degree to which the frequency of each TVS is stationary throughout the observation record, Figure 13 shows the number of occurrences for each TVS by season. Because each season has three months, the maximum number of times a given TVS can occur in a season is three. While there is no obvious trend in any of the four TVSs in either season, some low-frequency variability is suggested for DJF (Figure 13a). TVS2 and TVS3 tend to be more common in the first (1980-1990) and last (20032015) thirds of the times series whereas the middle third shows a predominance of TVS4. This is suggestive of decadal scale variability in monthly TVS occurrence. Interestingly, TVS2 and TVS3 are similar but opposite in sign, indicating that during roughly the first and last decades of the study period, temperature variability was more commonly characterized by a warm north and cold south or a cold north and warm south. During the middle decade, the generally cold TVS4 dominated, indicating a period of cooler DJF temperatures. It is not immediately apparent what the source of this semi-decadal scale variability is and a longer record would determine if this is part of a regular pattern of temperature variability.

In JJA (Figure 13b), interannual variability is dominant, with less indication of lower frequency variability in TVS occurrence compared with DJF. Several years do show all three months assigned to the same TVS, suggesting some seasonal scale forcing may influence the persistence of the synoptic-scale meteorological patterns that drive 
these TVSs. However, it is unclear from this analysis exactly what the source of that influence is.

\subsection{Influence of recurrent modes of climate variability on TVSS}

\section{4.a. $M E I$}

One potential source of inter-annual variability in TVS occurrence is from Pacific Ocean sea surface temperature forcing. To assess whether this influences the TVSs described here, Figure $14(a, b)$ shows the MEI value for each month belonging to each of the four TVSs. During DJF (Figure 14a), TVS4 shows a tendency to occur during the warm phase of ENSO, with a large proportion of TVS months concurrent with positive MEI values. While this relationship is not absolute, it does connect qualitatively with some of the interannual variability in Figure 13a. For example, the strong El Niño event of 1997-1998 shows two out of three months belonging to TVS4 in Figure 14a. Similarly, for JJA, TVS1 shows a strong relationship with positive MEI values. In Figure 14b, the winter preceding the strong 1997-1998 and 2015-2016 El Niño events show a predominance of TVS1 occurrences. The other three TVSs for both seasons exhibit, on average, a weak relationship with the MEI. While ENSO has an established connection to extreme temperature months along the northwestern coast of South America (Loikith et al., 2017), its teleconnection impact on temperature variability in SSA is less direct.

\section{4.b. SAM}

While ENSO is known to have the largest impact on temperature to the north of SSA, the SAM has been shown to be more directly related to temperature variability over 
SSA (Garreaud et al., 2009; Gillett et al., 2006). Figure 14(c,d) show the relationship between TVS and the SAM index in the same format as for the MEI in Figure 14(a,b). In DJF, TVS3 is associated with a positive SAM, while in JJA, TVS2 tends to be more associated with a positive SAM and TVS3 with a negative SAM. This is consistent with the known temperature impacts of the SAM as TVS2 is characterized by warm anomalies over much of the domain, with the strongest warm anomalies in the south, and TVS3 is characterized by strong cold anomalies in the south. These are both characteristic of the known relationship between temperature and the SAM here, however the lack of a strongly robust connection between TVS and the SAM is also consistent with other studies showing a modest impact between the SAM and monthly scale temperature variability in this region (Loikith et al., 2017). 


\section{Chapter 4: Summary and Conclusions}

In this study k-means clustering is used to highlight four primary monthly temperature anomaly variability states (TVSs) over southern South America for winter (JJA) and summer (DJF) and to investigate the concurrent meteorological conditions that are associated with these spatio-temporal patterns of temperature variability. In DJF the four climate variability states (Figure 4) are characterized by two spatially homogenous (same sign of temperature anomaly throughout the domain) and two north-south dipole patterns of temperature anomalies (opposite signed anomaly in the north compared with the south). In order to diagnose the associated meteorology for the TVSs, composite $\mathrm{Z} 850$ and $850 \mathrm{hPa}$ wind (Figure 5), integrated water vapor (Figure 6), and precipitation (Figure 7) are investigated for all months assigned to each of the four clusters. During DJF these synoptic meteorological drivers are found to have a well-defined connection to temperature patterns throughout the region. Lower tropospheric temperature and moisture advection, which can readily be connected to the wind at $850 \mathrm{hPa}$, is found to be strongly associated with temperature variability at the regional scale.

In JJA the TVSs (Figure 8) tend to exhibit a similar character to DJF with two TVSs dominated by the same sign anomaly throughout the domain (one cold and one warm) and two with north south dipoles. During JJA $850 \mathrm{hPa}$ wind (Figure 9) is still closely linked to temperature variability through advection in addition to low level transport of water vapor (Figure 11). In JJA, the meridional shift of the jet stream also shows a clear relationship with the TVSs (Figure 10), and helps diagnose poleward and equatorward excursions of anomalously warm and cold airmasses, respectively. 
Precipitation is likely linked with temperature variability (Figure 12) through mid-latitude cyclones forming along temperature gradients.

Interannual variability in TVS frequency of occurrence generally does not exhibit a clear temporal pattern over the data record analyzed here, however some TVSs are more common during some decades than others in DJF (Figure 13). This finding is suggestive of lower-frequency climate variability as influential on monthly-scale temperature variability over southern South America during DJF, although a clear mechanism is not apparent. At shorter timescales, the sign of ENSO shows some relationship with the frequency of occurrence of certain TVSs during some seasons, although the generally modest relationship suggests that the primary drivers of the TVSs are synoptic scale weather fluctuations that are not robustly connected to either climate mode (Figure 14). Other known modes of climate variability may also play a role, e.g. the Pacific Decadal Oscillation (Zhang et al., 1997) in temperature variability, however the relatively modest relationship between the SAM and ENSO, two modes documented as important for South America, suggests that the these relationships would be even weaker.

Results from this study can aide in advancing the understanding of key meteorological drivers of temperature variability over SSA. Furthermore, a more comprehensive understanding of the synoptic climatology of the region will provide a foundation for interpreting projections of future climate. For example, climate models can be evaluated by quantifying the degree to which they reproduce these TVSs in simulations of the historical past. If a model is able to realistically reproduce the TVSs and the associated SSMPs, that would boost confidence in the ability of the model to simulate temperature and the driving mechanisms of temperature variability over the 
region. If systematic changes in the TVSs and/or their associated meteorology are projected by climate model simulations of the future climate under enhanced greenhouse warming, this would provide a mechanistic view of climate change for the region. For example, if one TVS is projected to become more common, this may indicate non-linear changes in temperature over some regions, rather than just a uniform warm shift to the temperature probability distribution. These topics warrant further investigation. 
Figures
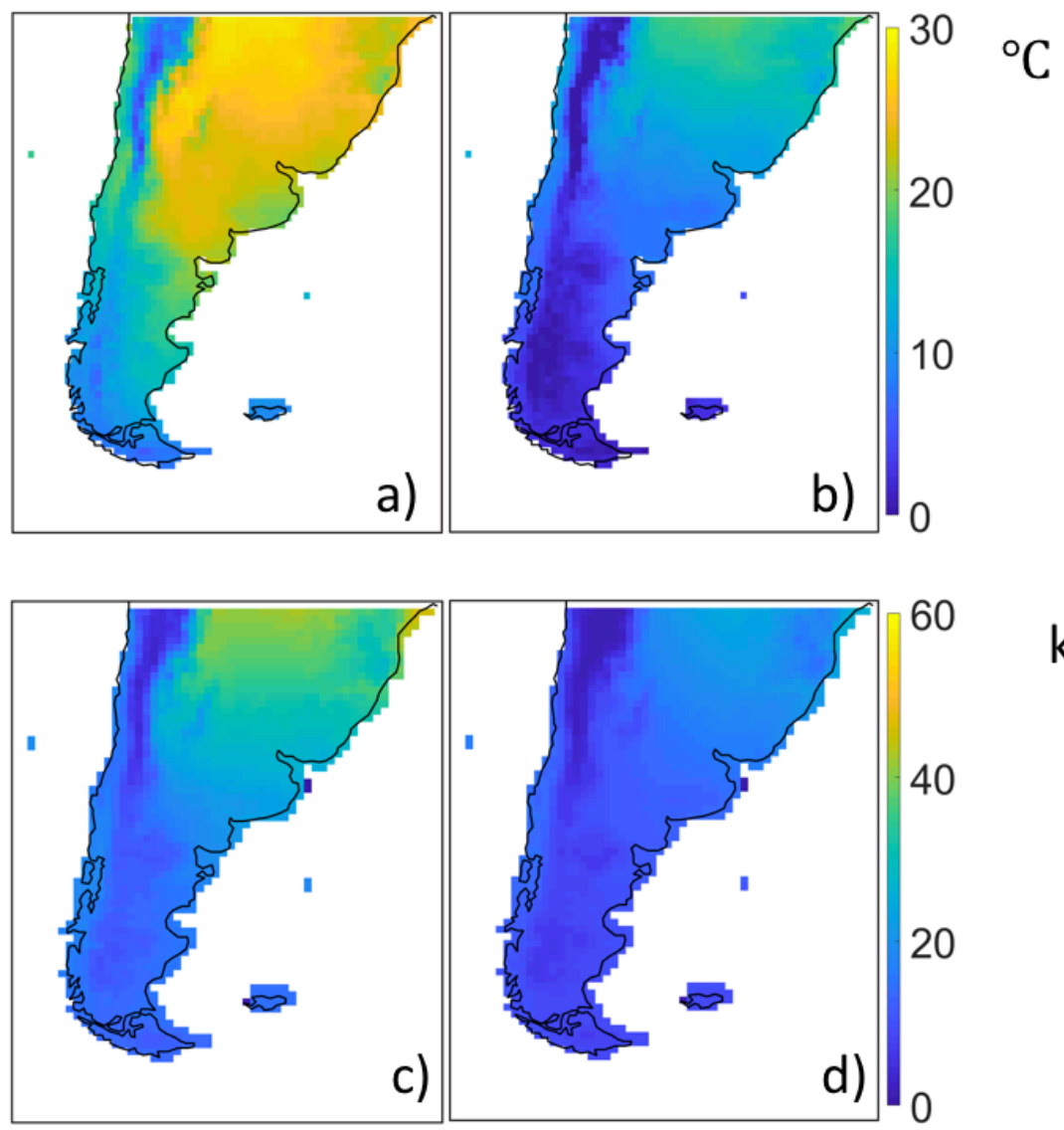

$\mathrm{kg} \mathrm{m-2}$
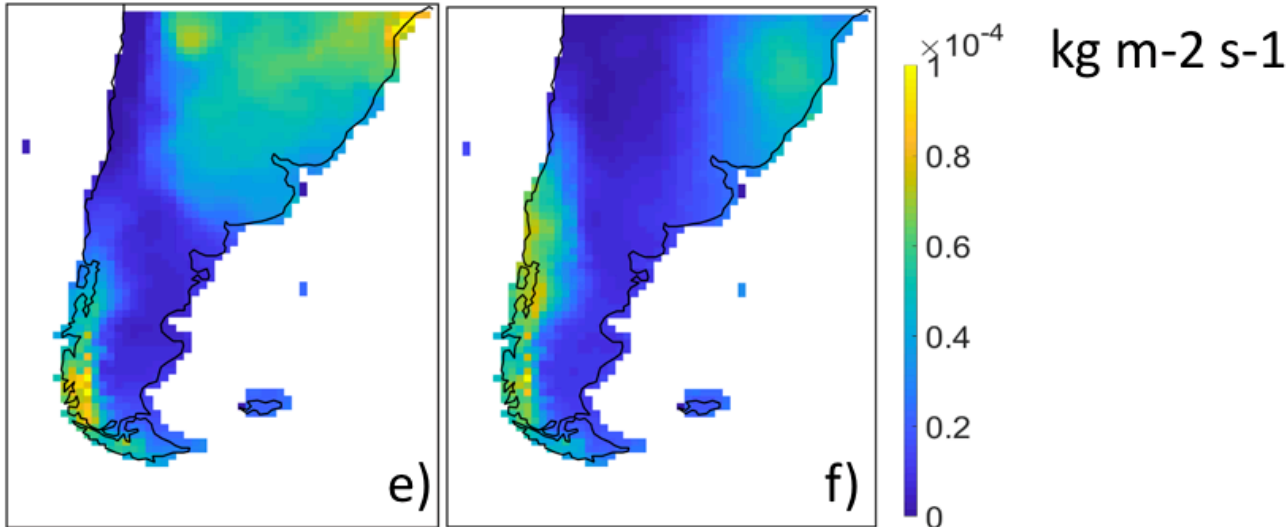

Figure 1. Total field composites for three meteorological variables separated by season:

Surface temperature, DJF (a) and JJA (b); Integrated water vapor, DJF (c) and JJA (d);

Precipitation, DJF (e) and JJA (f). Domain is between $23.5^{\circ} \mathrm{S}-60^{\circ} \mathrm{S}$ and $80^{\circ} \mathrm{W}-45^{\circ} \mathrm{W}$. 


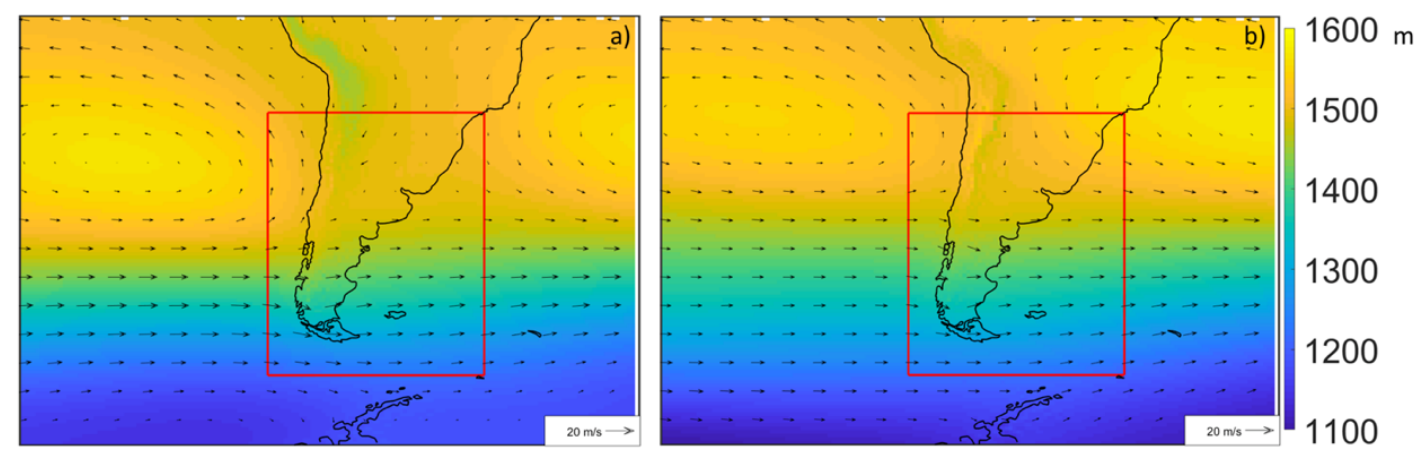

Figure 2. Total field geopotential height composites at $850 \mathrm{hPa}$ with wind at $850 \mathrm{hPa}$ layered (Z850) over top. Fields are separated into DJF (a) and JJA (b). Domain is between $10^{\circ} \mathrm{S}-70^{\circ} \mathrm{S}$ and $120^{\circ} \mathrm{W}-20^{\circ} \mathrm{W}$.

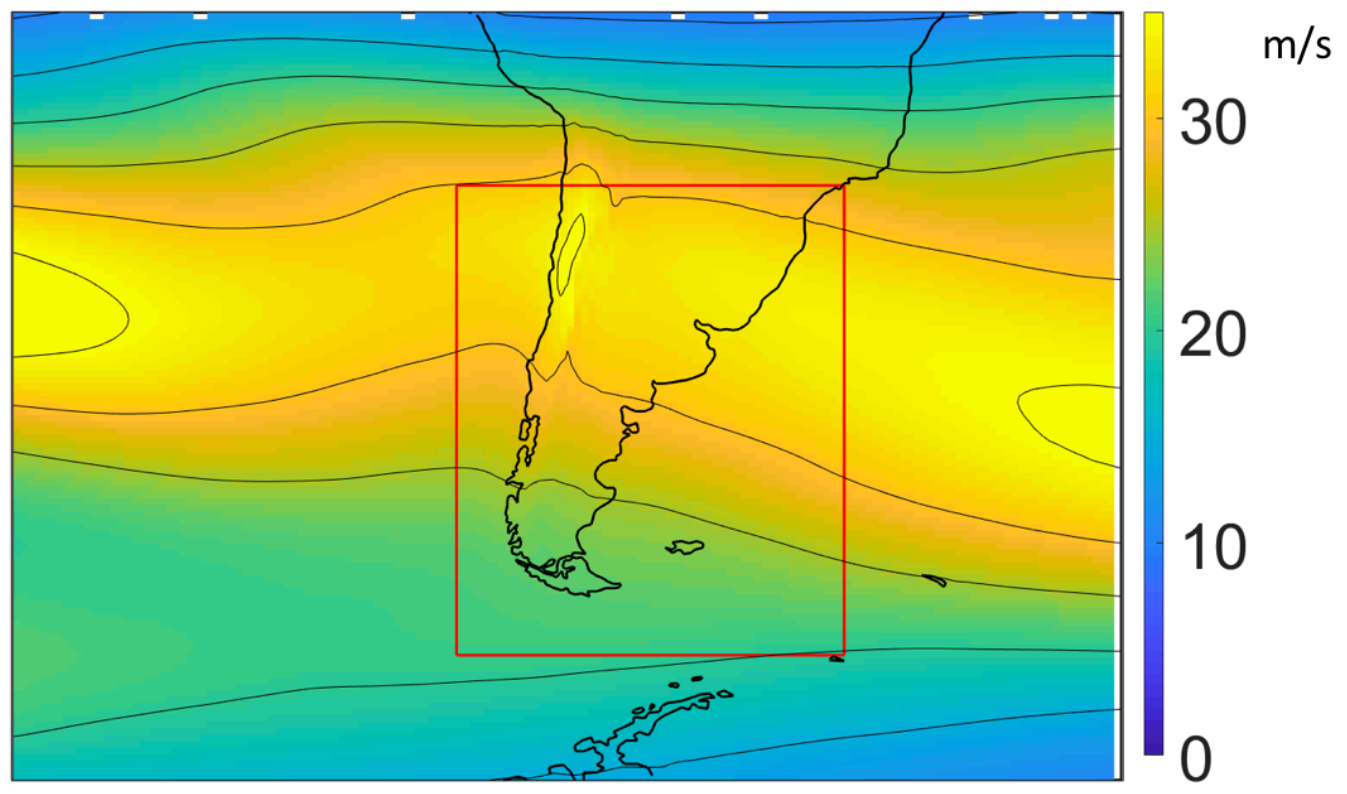

Figure 3. Total field wind speed composite at $250 \mathrm{hPa}$ for JJA only. Contours are at $5 \mathrm{~m} / \mathrm{s}$ intervals. Domain is between $10^{\circ} \mathrm{S}-70^{\circ} \mathrm{S}$ and $120^{\circ} \mathrm{W}-20^{\circ} \mathrm{W}$. 


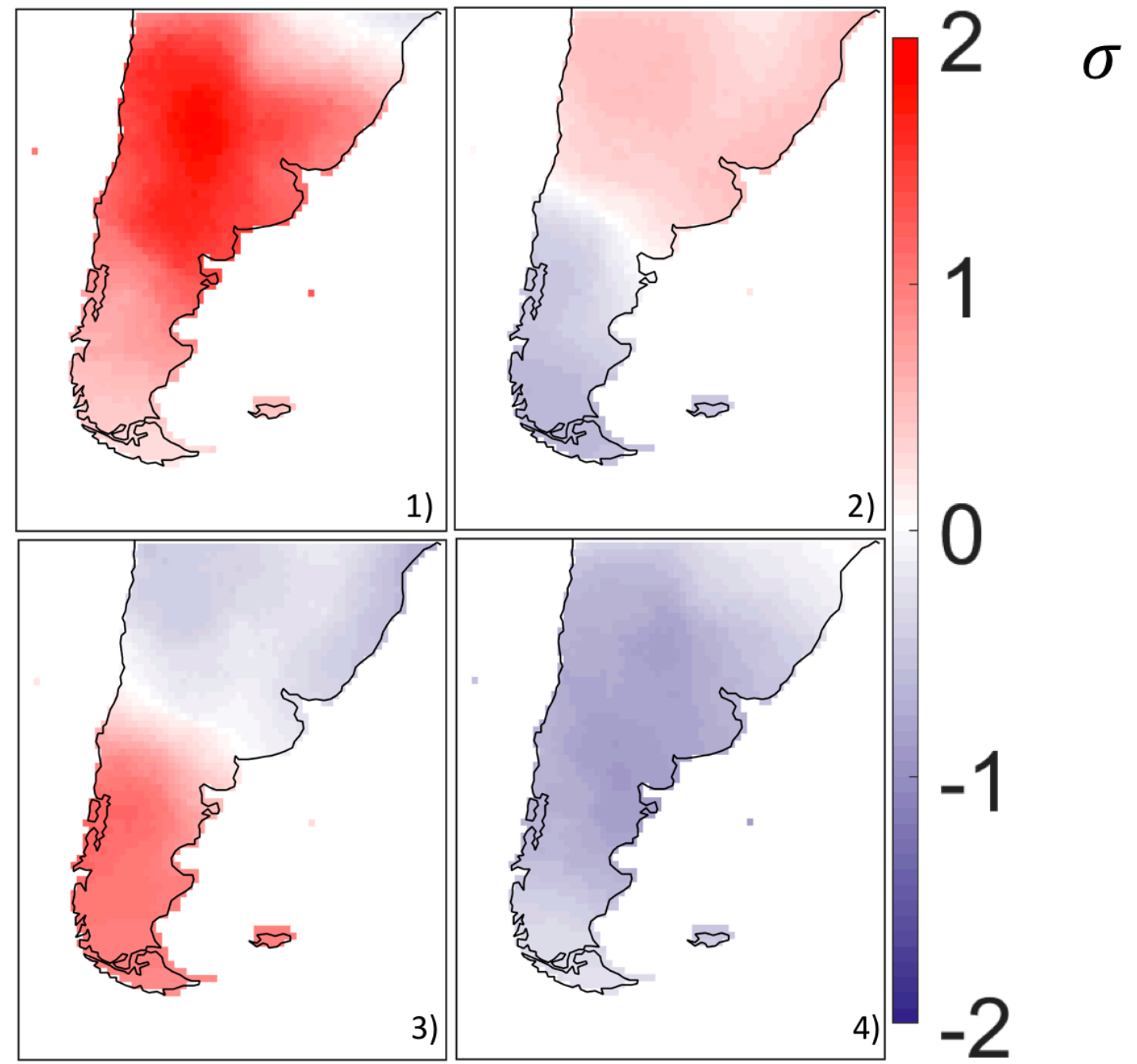

Figure 4. TVSs for DJF, these composites are normalized anomalies and characterize surface temperature variability patterns in order to identify dominant modes. Domain is between $23.5^{\circ} \mathrm{S}-60^{\circ} \mathrm{S}$ and $80^{\circ} \mathrm{W}-45^{\circ} \mathrm{W}$. 


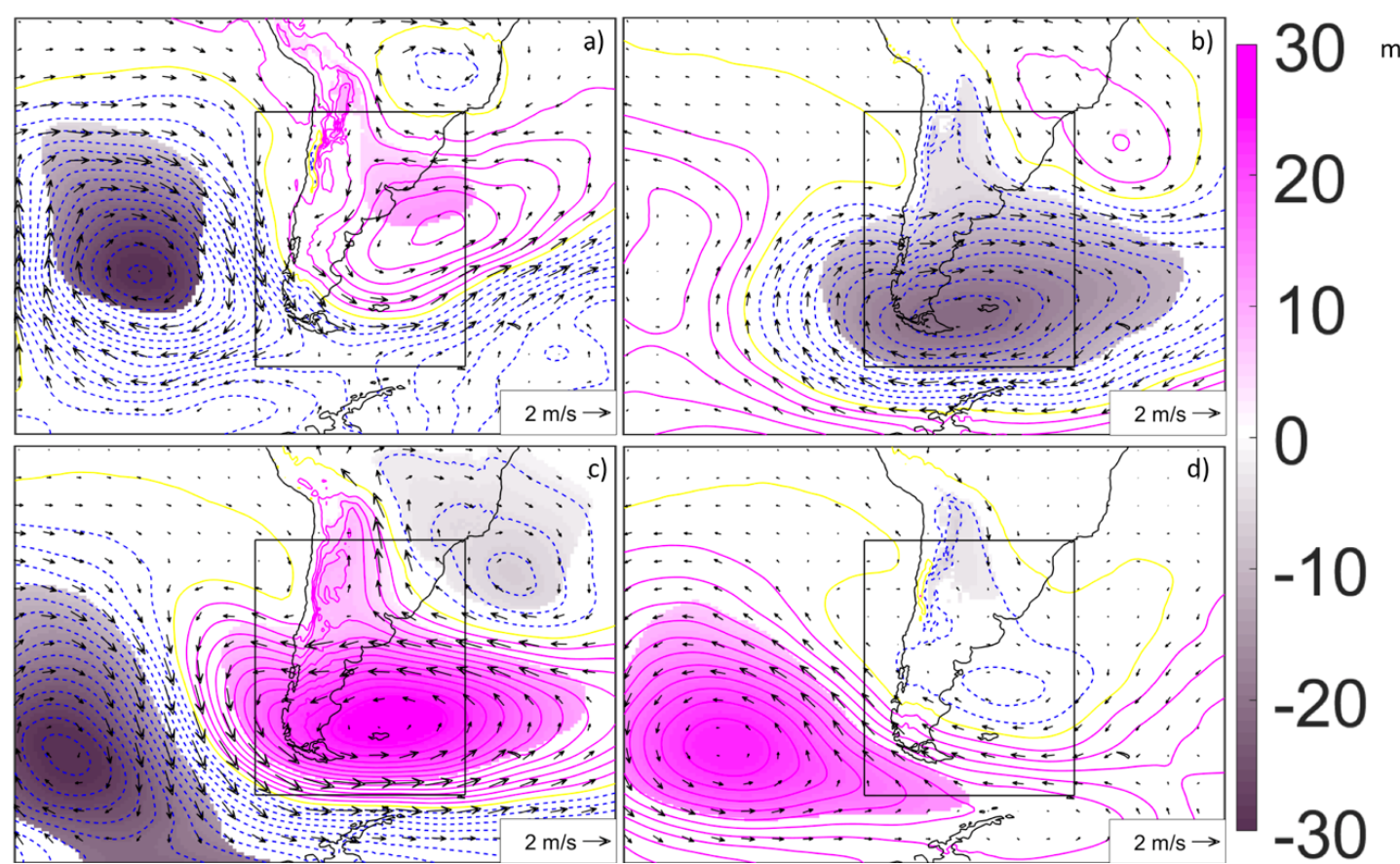

Figure 5. DJF composites of geopotential height anomalies and wind anomalies at 850

$\mathrm{hPa}$. Shaded regions are statistically significant. Solid magenta line indicates regions of positive Z850 anomalies; solid yellow line indicates the zero line of Z850 anomalies; dashed blue line indicates negative Z850 anomalies. Contours are spaced every 3 meters. Domain is between $10^{\circ} \mathrm{S}-70^{\circ} \mathrm{S}$ and $120^{\circ} \mathrm{W}-20^{\circ} \mathrm{W}$. 


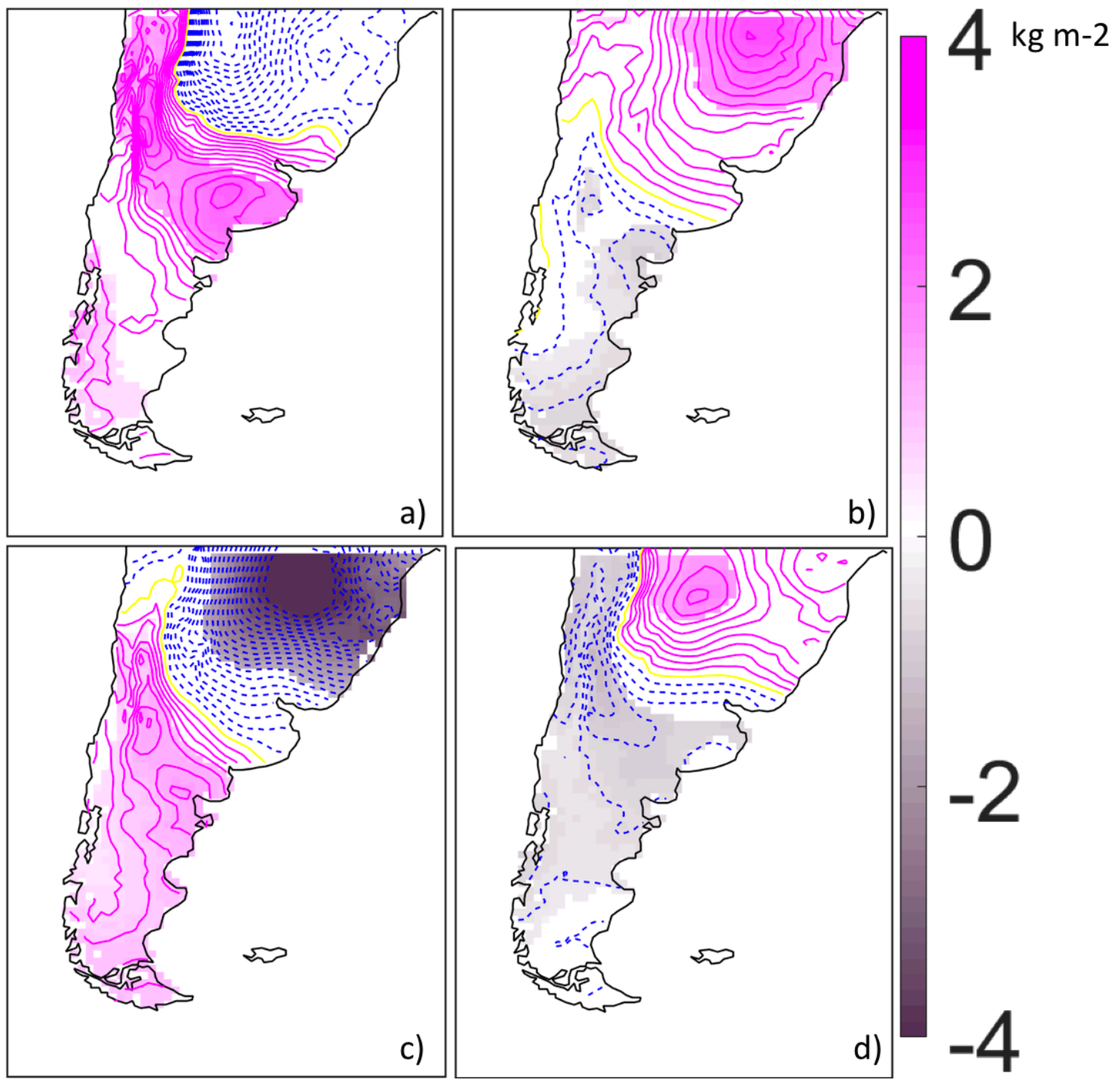

Figure 6. Anomalies of integrated water vapor during DJF. Solid magenta line: positive Z850 anomalies; solid yellow line: zero line of anomalies; dashed blue line: negative anomalies. Contours are spaced every $.5 \mathrm{~kg} \mathrm{~m}-2$. Domain is between $23.5^{\circ} \mathrm{S}-60^{\circ} \mathrm{S}$ and $80^{\circ} \mathrm{W}-45^{\circ} \mathrm{W}$ 

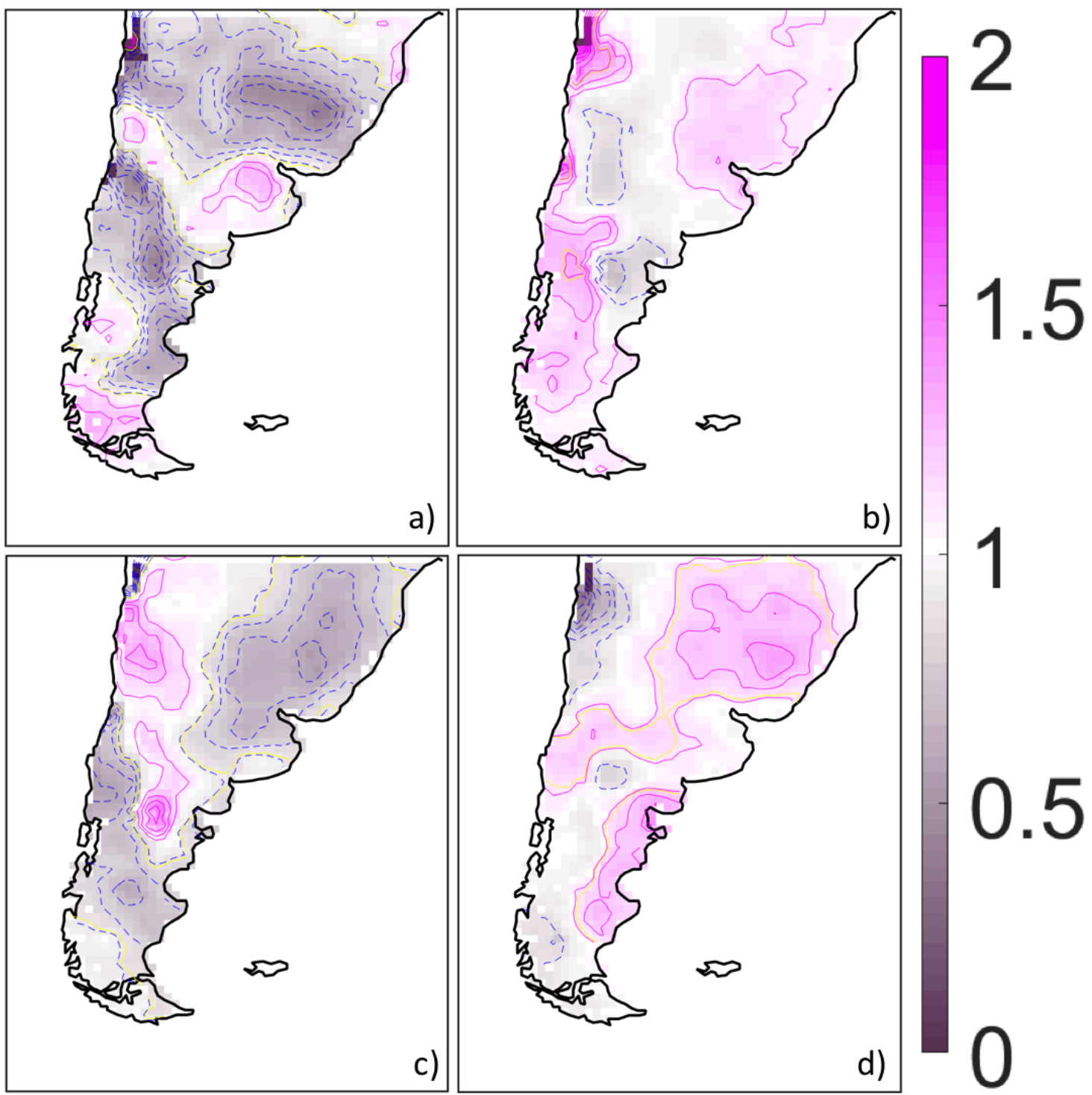

1

0.5

Figure 7. DJF precipitation fraction (a unitless scale) where a value greater than 1 (solid magenta line) indicates positive anomalies, a value equal to 1 (solid yellow line) indicates no anomalies, and a value less than 1 (dashed blue line) indicates negative anomalies. Contours are spaced every .2 (unitless). Domain is between $23.5^{\circ} \mathrm{S}-60^{\circ} \mathrm{S}$ and $80^{\circ} \mathrm{W}-$ $45^{\circ} \mathrm{W}$ 


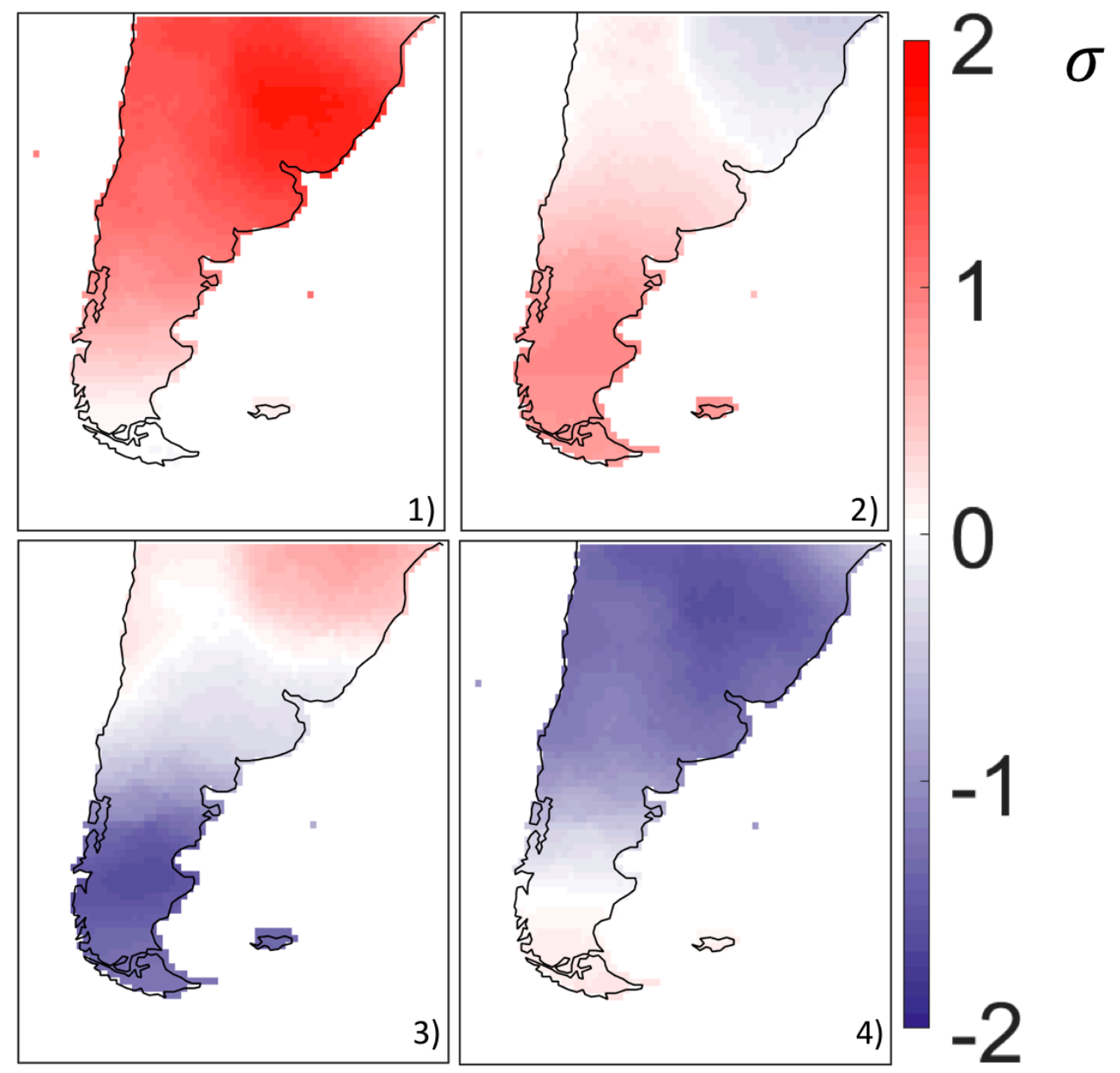

Figure 8. Same as Figure 4 except for JJA. 


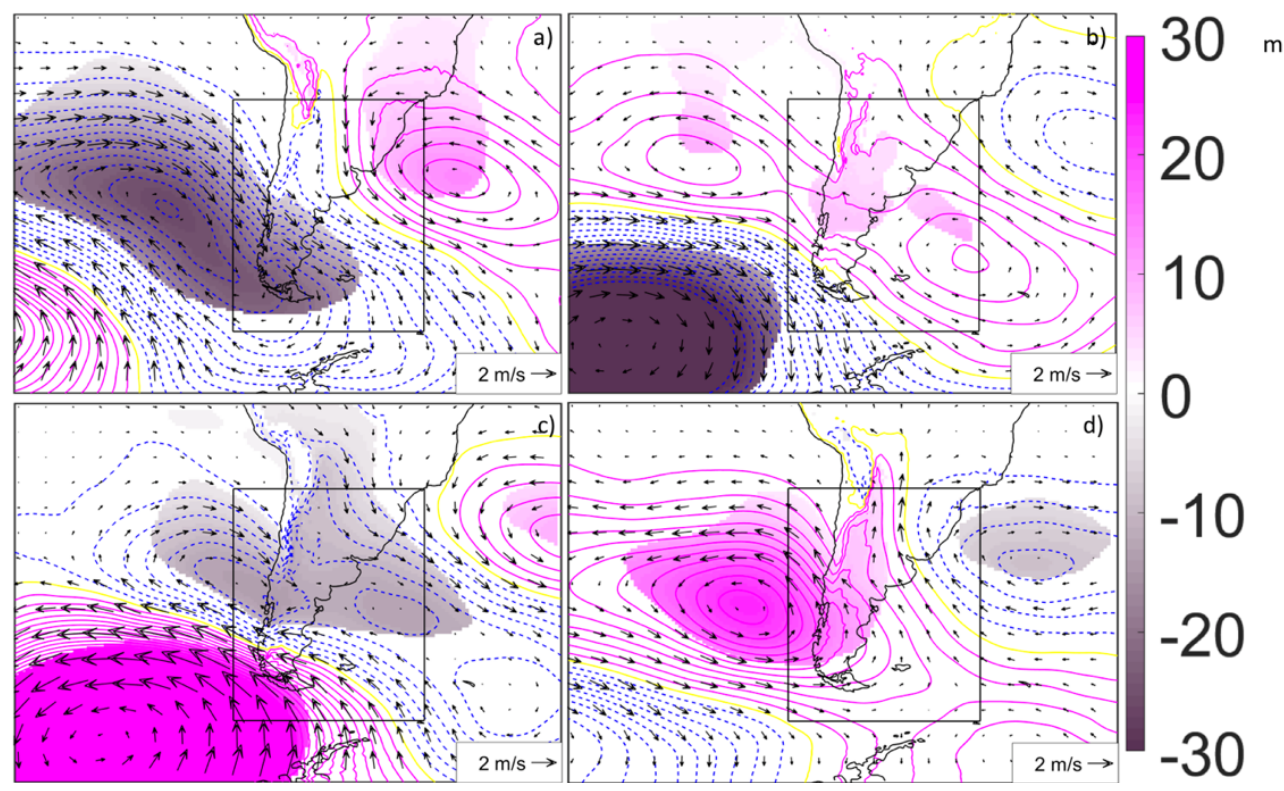

Figure 9. Same as 5 except for JJA.
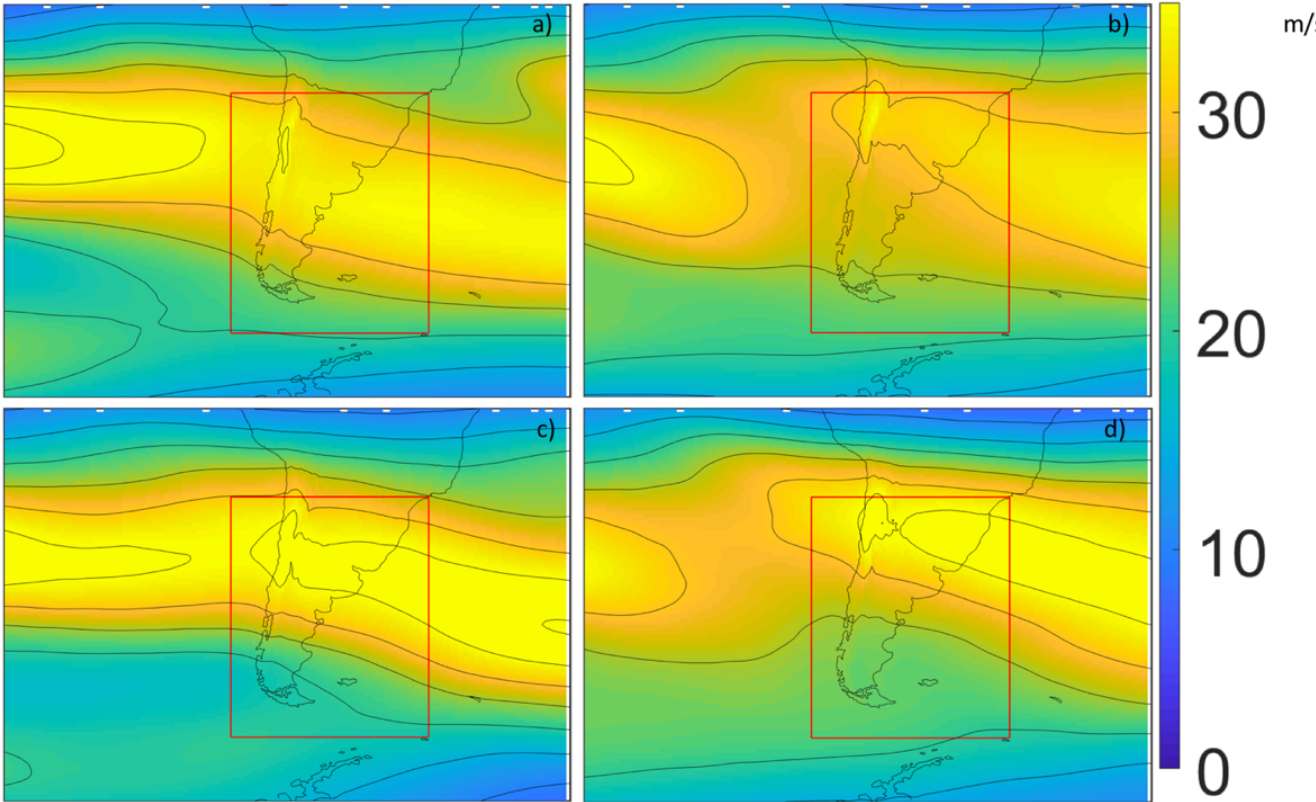

Figure 10 . Wind speed at $250 \mathrm{hPa}$ for JJA, indicating placement of the jet stream. 


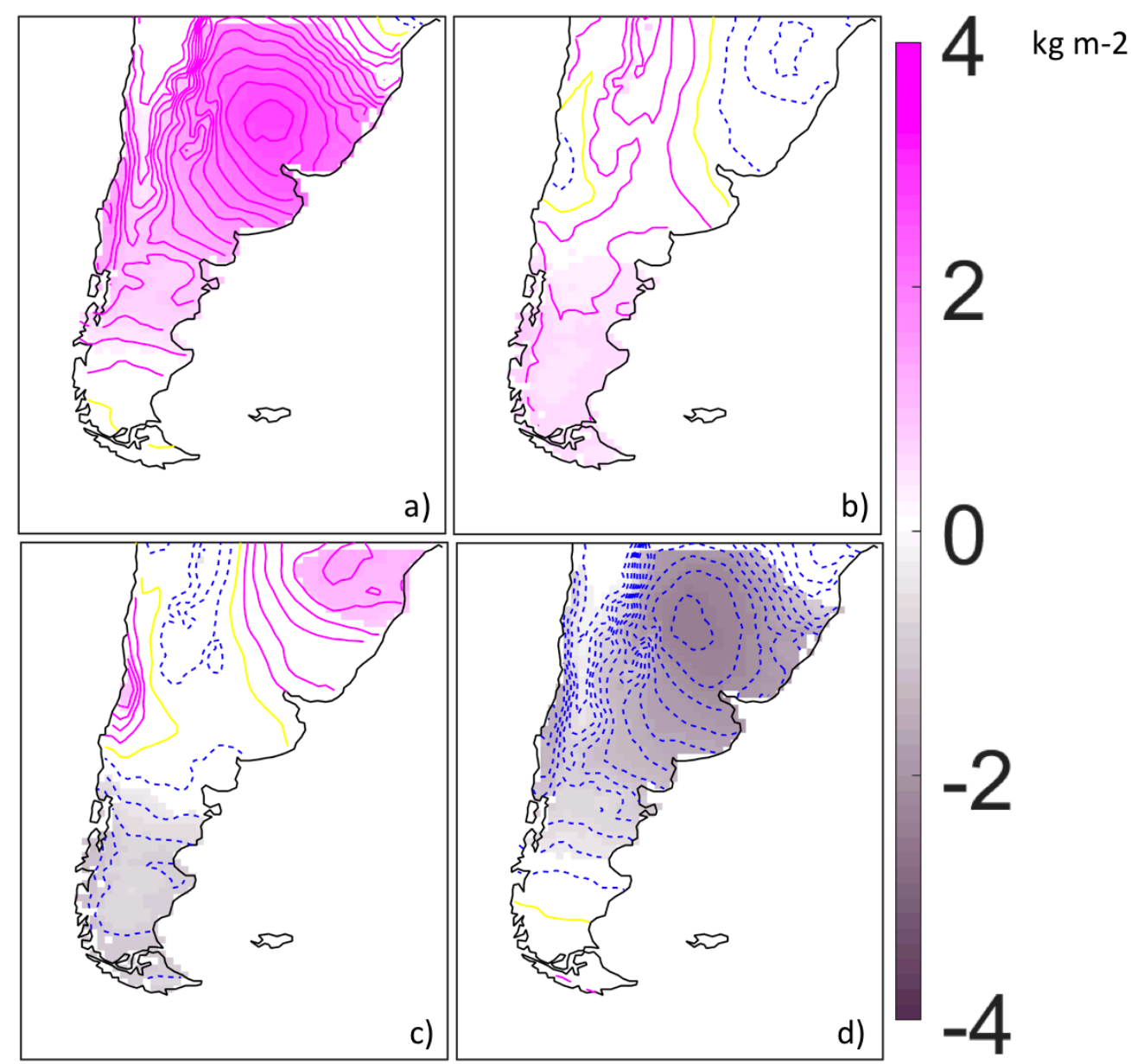

Figure 11. Same as Figure 6 except for JJA. 

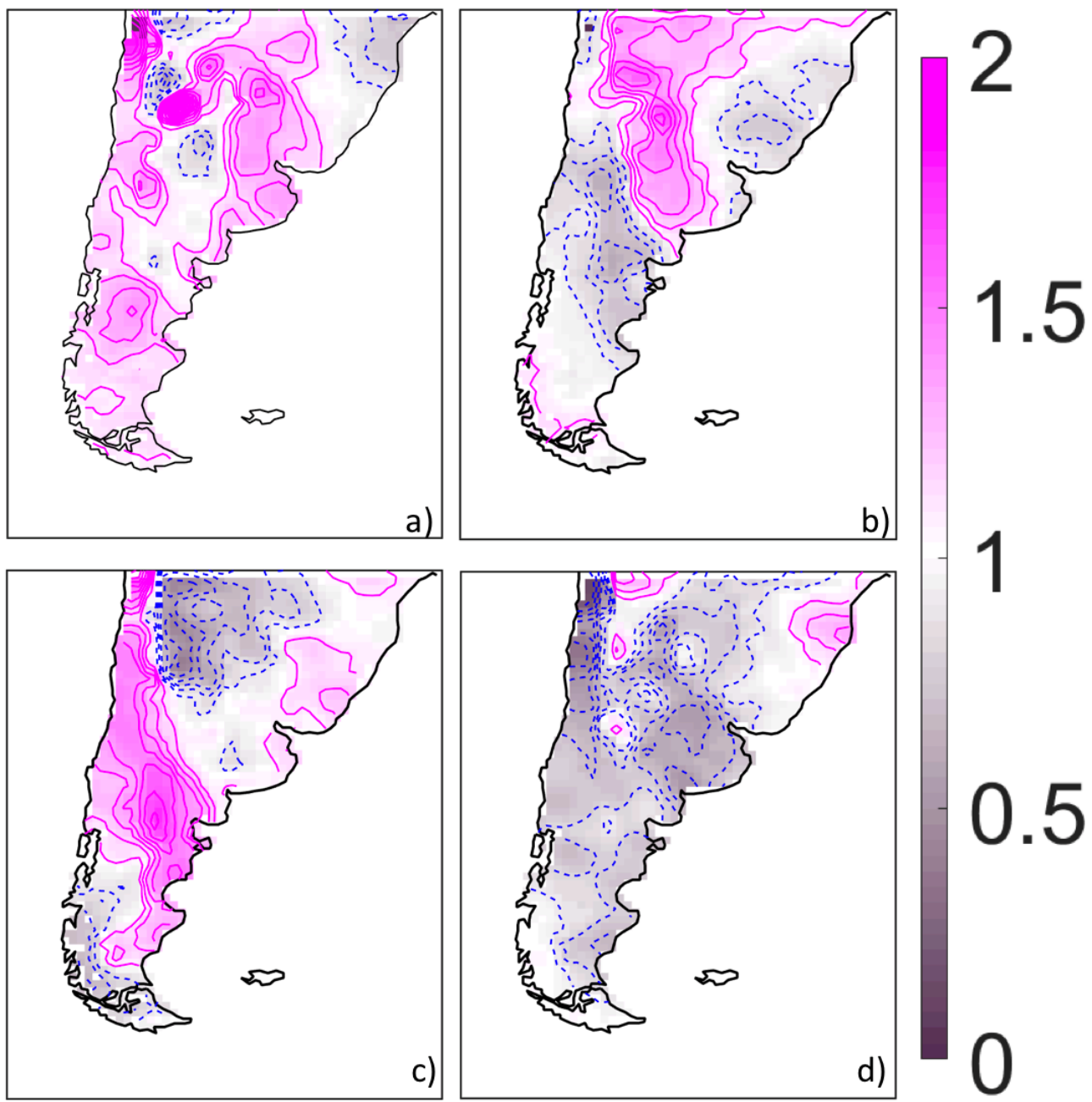

Figure 12. Same as Figure 7 except for JJA. 

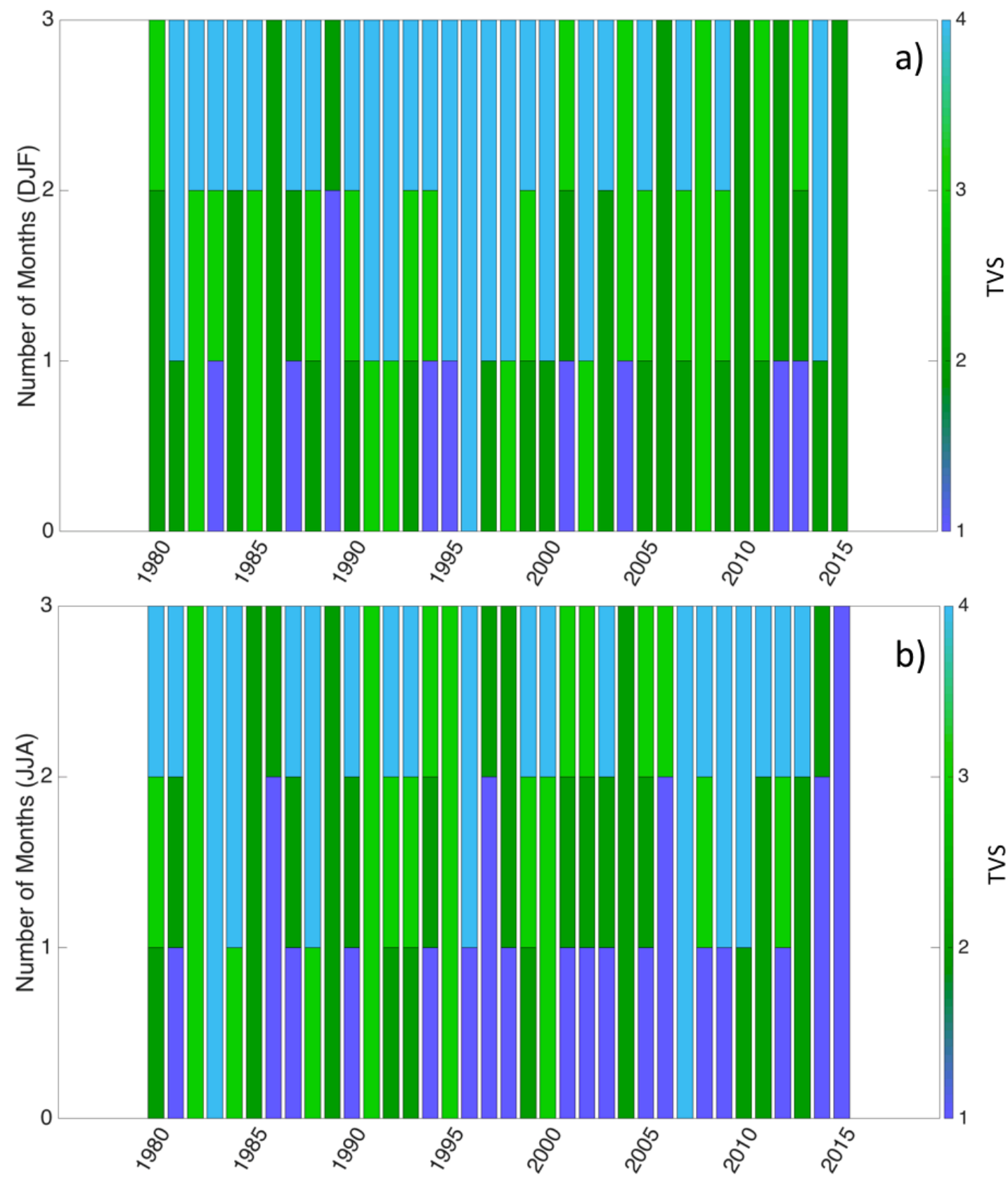

Figure 13. Here the possibility that some clusters may be occurring more frequently over the course of the study period is investigated. This is accomplished by counting how often each TVS occurs each year, for each season. Here a stacked bar graph is used to investigate the interannual to interdecadal variability of the TVSs by observing how frequently each state occurs. 

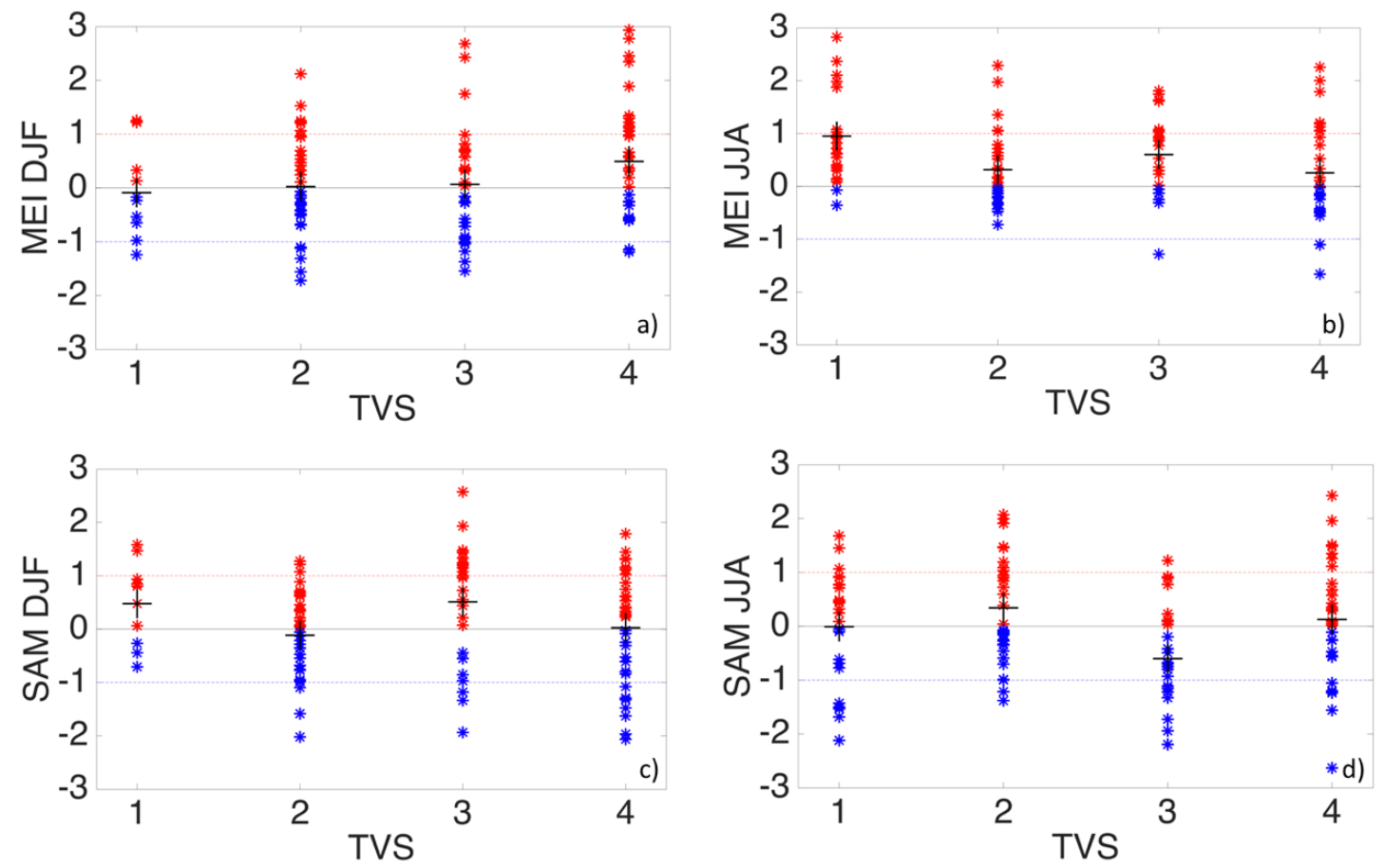

Figure 14. The recurrent mode of climate variability index (ENSO and SAM) values associated with the months assigned to each TVS are plotted for each season. The black cross in each TVS grouping is the mean of the index values associated with each TVS. 


\section{References}

Aliaga, V. S., Ferrelli, F., \& Piccolo, M. C. (2017). Regionalization of climate over the Argentine Pampas. International Journal of Climatology, 37(S1), 1237-1247.

Barkhordarian, A., von Storch, H., Zorita, E., Loikith, P. C., \& Mechoso, C. R. (2017). Observed warming over northern South America has an anthropogenic origin. Climate Dynamics, 1-14.

Berman, A. L., Silvestri, G., \& Compagnucci, R. (2013). On the variability of seasonal temperature in southern South America. Climate dynamics, 40(7-8), 1863-1878.

Bradley, R. S., Keimig, F. T., Diaz, H. F., \& Hardy, D. R. (2009). Recent changes in freezing level heights in the Tropics with implications for the deglacierization of high mountain regions. Geophysical Research Letters, 36(17).

Buytaert, W. O. U. T. E. R., \& Breuer, L. U. T. Z. (2013). Water resources in South America: sources and supply, pollutants and perspectives. Understanding Freshwater Quality Problems in a Changing World. IAHS publications, 359.

Cassano, J. J., Cassano, E. N., Seefeldt, M. W., Gutowski Jr, W. J., \& Glisan, J. M. (2016). Synoptic conditions during wintertime temperature extremes in Alaska. Journal of Geophysical Research: Atmospheres, 121(7), 3241-3262. 
de Barros Soares, D., Lee, H., Loikith, P. C., Barkhordarian, A., \& Mechoso, C. R. (2017). Can significant trends be detected in surface air temperature and precipitation over South America in recent decades?. International Journal of Climatology, 37(3), 1483-1493.

Dee, D. P., Uppala, S. M., Simmons, A. J., Berrisford, P., Poli, P., Kobayashi, S., ... \& Bechtold, P. (2011). The ERA-Interim reanalysis: Configuration and performance of the data assimilation system. Quarterly Journal of the royal meteorological society, 137(656), 553-597.

Flato, G., Marotzke, J., Abiodun, B., Braconnot, P., Chou, S. C., Collins, W. J., ... \& Forest, C. (2013). Evaluation of Climate Models. In: Climate Change 2013: The Physical Science Basis. Contribution of Working Group I to the Fifth Assessment Report of the Intergovernmental Panel on Climate Change. Climate Change $2013,5,741-866$.

Garreaud, R. D. (2009). The Andes climate and weather. Advances in Geosciences, 22, 311.

Garreaud, R. D., Vuille, M., Compagnucci, R., \& Marengo, J. (2009). Present-day south american climate. Palaeogeography, Palaeoclimatology, Palaeoecology, 281(3-4), 180-195. 
Gelaro, R., McCarty, W., Suárez, M. J., Todling, R., Molod, A., Takacs, L., ... \& Wargan, K. (2017). The modern-era retrospective analysis for research and applications, version 2 (MERRA-2). Journal of Climate, 30(14), 5419-5454.

Gillett, N. P., Kell, T. D., \& Jones, P. D. (2006). Regional climate impacts of the Southern Annular Mode. Geophysical Research Letters, 33(23).

Grimm, A. M., Barros, V. R., \& Doyle, M. E. (2000). Climate variability in southern South America associated with El Niño and La Niña events. Journal of climate, 13(1), 35-58.

Grimm, A. M., \& Tedeschi, R. G. (2009). ENSO and extreme rainfall events in South America. Journal of Climate, 22(7), 1589-1609.

Harris, I. P. D. J., Jones, P. D., Osborn, T. J., \& Lister, D. H. (2014). Updated highresolution grids of monthly climatic observations-the CRU TS3. 10 Dataset. International journal of climatology, 34(3), 623-642.

Kayano, M. T., Andreoli, R. V., de Souza, R. A. F., \& Garcia, S. R. (2017). Spatiotemporal variability modes of surface air temperature in South America during the 1951-2010 period: ENSO and non-ENSO components. International Journal of Climatology, 37(S1), 1-13. 
Lau, N. C., \& Nath, M. J. (2012). A model study of heat waves over North America: Meteorological aspects and projections for the twenty-first century. Journal of Climate, 25(14), 4761-4784.

Loikith, P. C., \& Broccoli, A. J. (2012). Characteristics of observed atmospheric circulation patterns associated with temperature extremes over North America. Journal of Climate, 25(20), 7266-7281.

Loikith, P. C., Detzer, J., Mechoso, C. R., Lee, H., \& Barkhordarian, A. (2017). The influence of recurrent modes of climate variability on the occurrence of monthly temperature extremes over South America. Journal of Geophysical Research: Atmospheres, 122(19).

MacQueen, J. (1967, June). Some methods for classification and analysis of multivariate observations. In Proceedings of the fifth Berkeley symposium on mathematical statistics and probability (Vol. 1, No. 14, pp. 281-297).

Marengo, J. A., Chou, S. C., Torres, R. R., Giarolla, A., Alves, L. M., \& Lyra, A. (2014). Climate change in central and South America: recent trends, future projections, and impacts on regional agriculture. 
Masiokas, M. H., Villalba, R., Luckman, B. H., Lascano, M. E., Delgado, S., \& Stepanek, P. (2008). 20th-century glacier recession and regional hydroclimatic changes in northwestern Patagonia. Global and Planetary Change, 60(1-2), 85-100.

New, M., Hulme, M., \& Jones, P. (2000). Representing twentieth-century space-time climate variability. Part II: Development of 1901-96 monthly grids of terrestrial surface climate. Journal of climate, 13(13), 2217-2238.

Pampuch, L. A., Drumond, A., Gimeno, L., \& Ambrizzi, T. (2016). Anomalous patterns of SST and moisture sources in the South Atlantic Ocean associated with dry events in southeastern Brazil. International Journal of Climatology, 36(15), 49134928.

Pezza, A. B., Van Rensch, P., \& Cai, W. (2012). Severe heat waves in Southern Australia: synoptic climatology and large scale connections. Climate Dynamics, 38(1-2), 209-224.

Rusticucci, M. (2012). Observed and simulated variability of extreme temperature events over South America. Atmospheric Research, 106, 1-17.

Silvestri, G., \& Vera, C. (2009). Nonstationary impacts of the southern annular mode on Southern Hemisphere climate. Journal of Climate, 22(22), 6142-6148. 
Solman, S. A., \& Menéndez, C. G. (2003). Weather regimes in the South American sector and neighbouring oceans during winter. Climate Dynamics, 21(1), 91-104.

Sura, P. (2011). A general perspective of extreme events in weather and climate. Atmospheric Research, 101(1-2), 1-21.

Thompson, D. W., \& Wallace, J. M. (2000). Annular modes in the extratropical circulation. Part I: Month-to-month variability. Journal of climate, 13(5), 10001016.

Torralba, V., Rodríguez-Fonseca, B., Mohino, E., \& Losada, T. (2015). The nonstationary influence of the Atlantic and Pacific Niños on North Eastern South American rainfall. Frontiers in Earth Science, 3, 55.

Wolter, K., \& Timlin, M. S. (1998). Measuring the strength of ENSO events: How does 1997/98 rank?. Weather, 53(9), 315-324.

Zhang, Y., Wallace, J. M., \& Battisti, D. S. (1997). ENSO-like interdecadal variability: 1900-93. Journal of climate, 10(5), 1004-1020. 


\section{Appendix: Supplemental Figures}

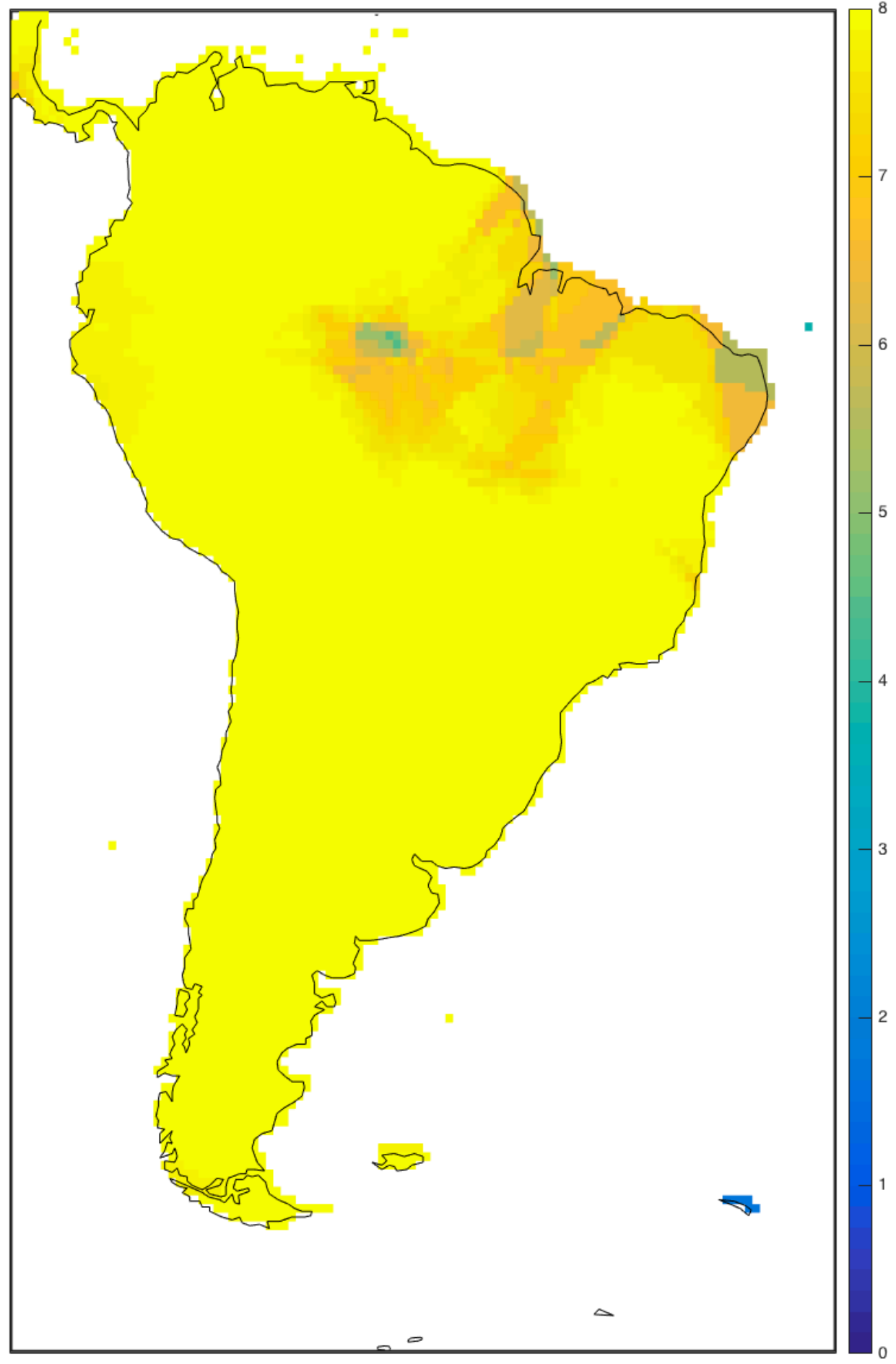

Figure S1. Average number of stations contributing to each grid cell. 


\section{ALTERNATE DATA SETS}

DJF
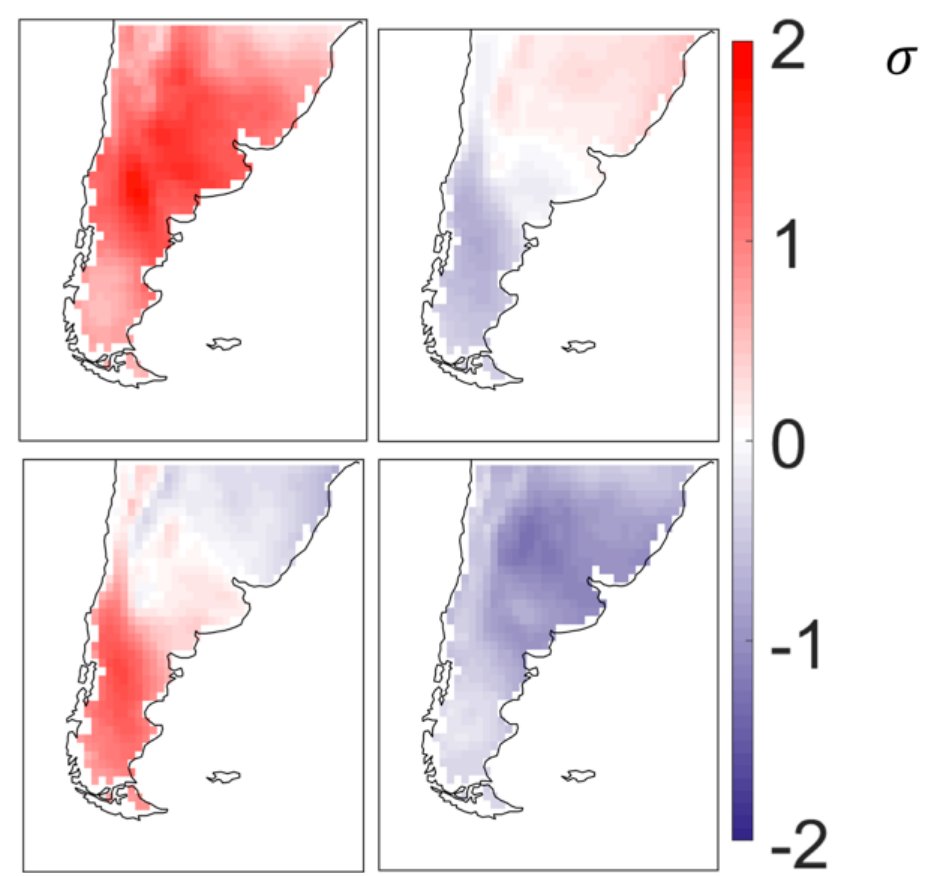

Figure S2. ERA-Interim surface temperature, DJF.
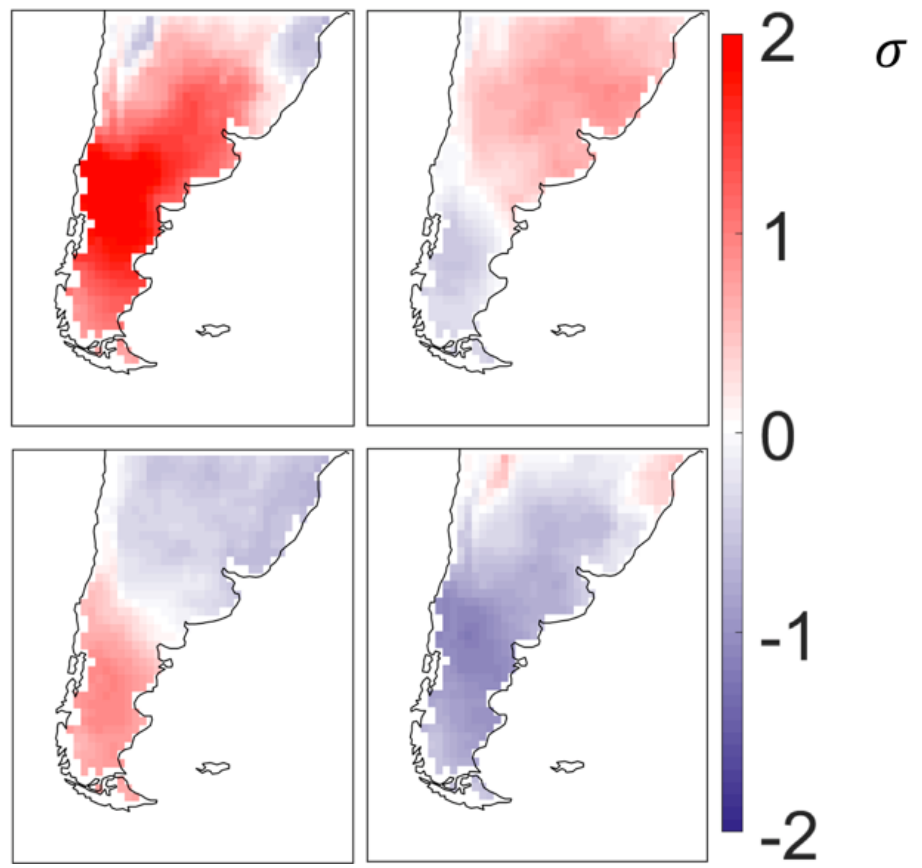

Figure S3. MERRA-2 temperature, DJF. 

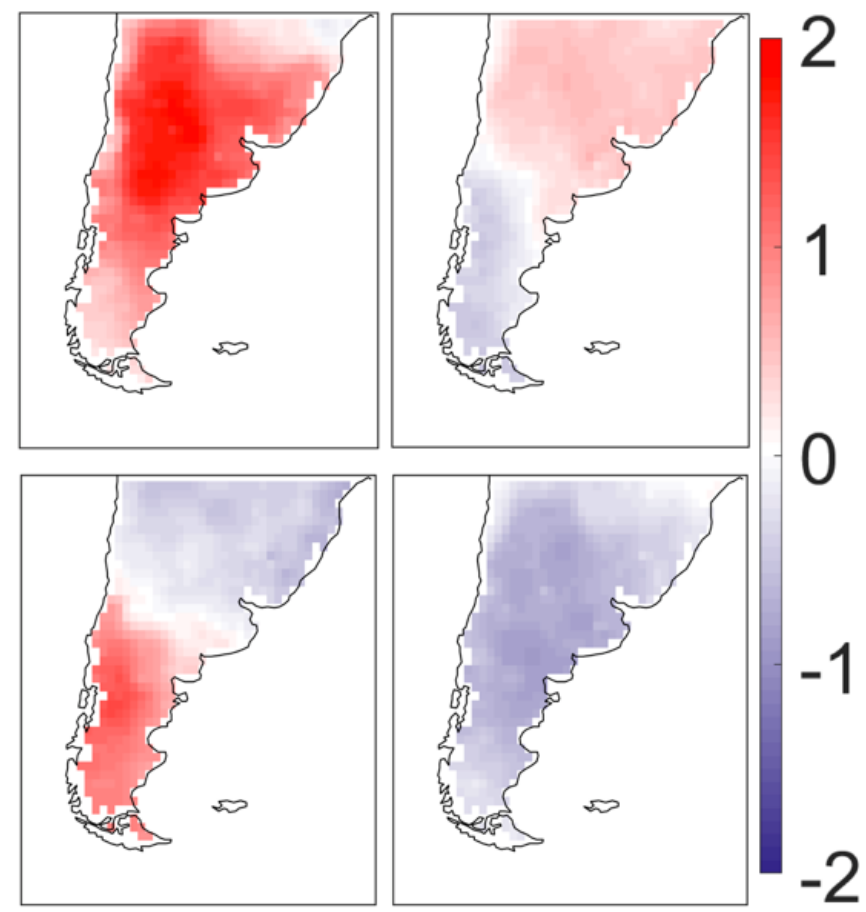

Figure S4. UDel surface temperature, DJF. 
JJA

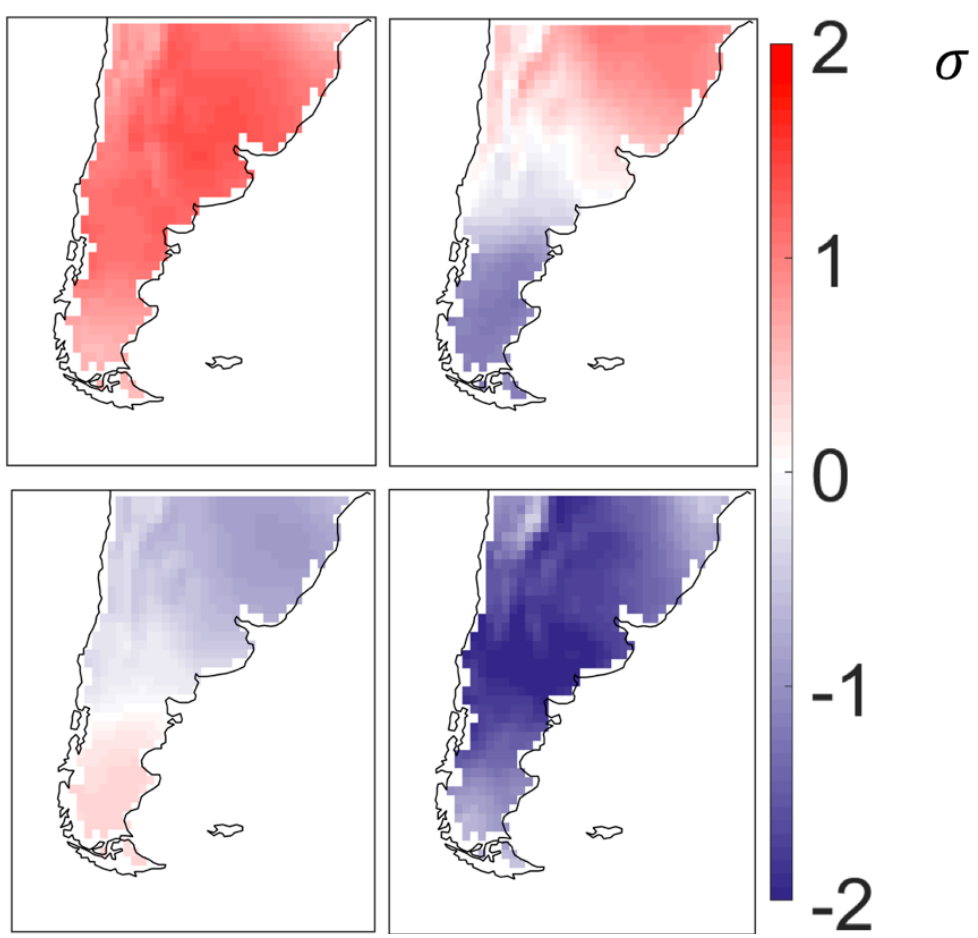

Figure S5. Same as Figure S2 except for JJA. 

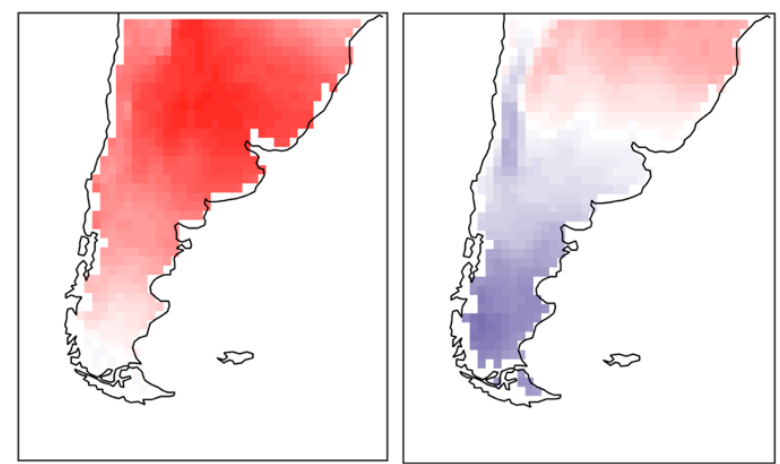

2

$\sigma$
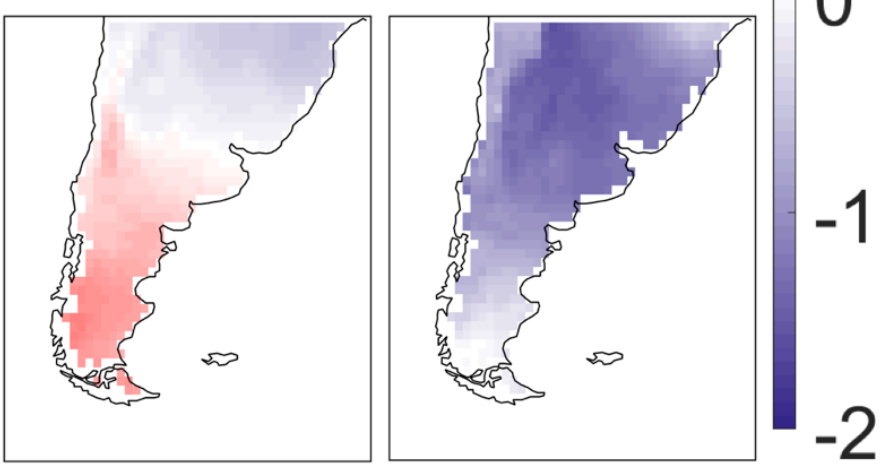

Figure S6. Same as Figure S3 except for JJA.
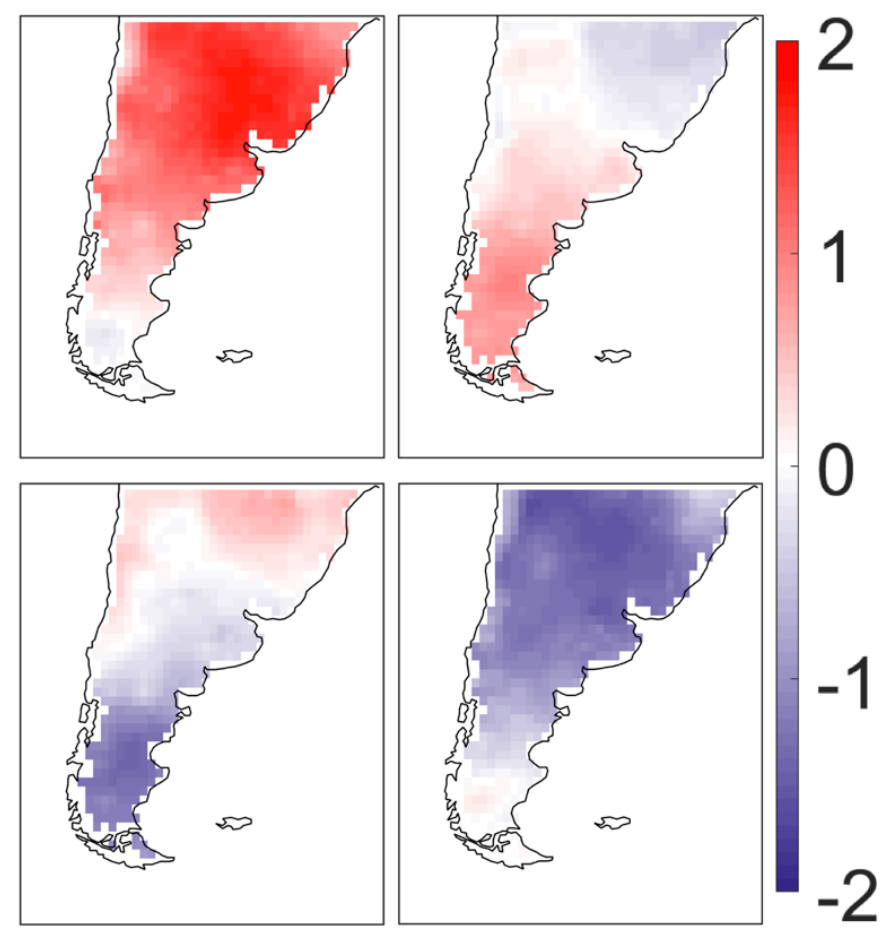

Figure S7. Same as Figure S4 except for JJA. 